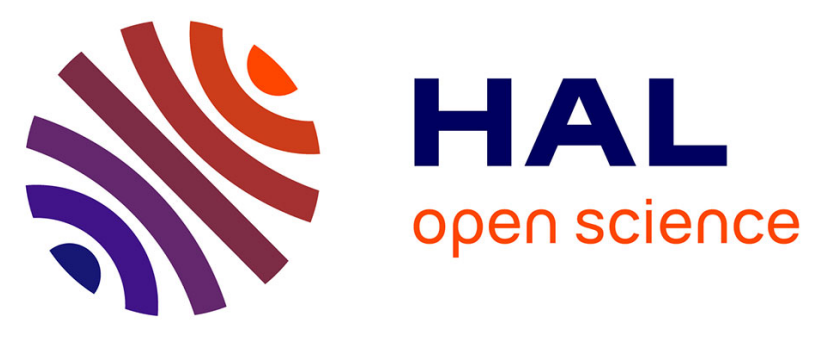

\title{
Discovery of genes that modulate flavivirus replication in an interferon-dependent manner
}

Sarah Lesage, Maxime Chazal, Guillaume Beauclair, Damien Batalie, Silvia

Cerboni, Elodie Couderc, Aurianne Lescure, Elaine del Nery, Frédéric Tangy, Annette Martin, et al.

\section{To cite this version:}

Sarah Lesage, Maxime Chazal, Guillaume Beauclair, Damien Batalie, Silvia Cerboni, et al.. Discovery of genes that modulate flavivirus replication in an interferon-dependent manner. Journal of Molecular Biology, 2021, pp.167277. 10.1016/j.jmb.2021.167277 . hal-03365436

\section{HAL Id: hal-03365436 https://hal.science/hal-03365436}

Submitted on 25 Jan 2022

HAL is a multi-disciplinary open access archive for the deposit and dissemination of scientific research documents, whether they are published or not. The documents may come from teaching and research institutions in France or abroad, or from public or private research centers.
L'archive ouverte pluridisciplinaire HAL, est destinée au dépôt et à la diffusion de documents scientifiques de niveau recherche, publiés ou non, émanant des établissements d'enseignement et de recherche français ou étrangers, des laboratoires publics ou privés. 


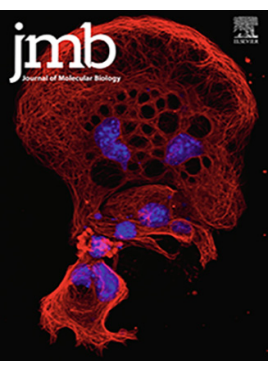

\title{
Discovery of Genes that Modulate Flavivirus Replication in an Interferon- Dependent Manner
}

\author{
Sarah Lesage ${ }^{1 \dagger}$, Maxime Chazal ${ }^{1 \dagger}$, Guillaume Beauclair ${ }^{1,2}$, Damien Batalie ${ }^{3}$, \\ Silvia Cerboni ${ }^{4}$, Elodie Couderc ${ }^{1,5}$, Aurianne Lescure ${ }^{6}$, Elaine Del Nery ${ }^{6}$, \\ Frédéric Tangy ${ }^{7}$, Annette Martin ${ }^{3}$, Nicolas Manel ${ }^{4 *}$ and Nolwenn Jouvenet ${ }^{1 *}$ \\ 1 - Institut Pasteur, Université de Paris, CNRS UMR 3569, Virus Sensing and Signaling Unit, F-75015 Paris, France \\ 2 - Université Paris-Saclay, CEA, CNRS, Institute for Integrative Biology of the Cell (I2BC), Gif-sur-Yvette, France \\ 3 - Institut Pasteur, Université de Paris, CNRS UMR 3569, Molecular Genetics of RNA Viruses Unit, F-75015 Paris, France \\ 4 - Institut Curie, PSL Research University, INSERM U932, Paris, France \\ 5 - Institut Pasteur, Université de Paris, CNRS UMR 2000, Insect-Virus Interactions Unit, F-75015 Paris, France \\ 6 - Institut Curie, PSL Research University, Department of Translational Research-Biophenics High-Content Screening \\ Laboratory, Cell and Tissue Imaging Facility (PICT-IBiSA), Paris, France \\ 7 - Institut Pasteur, Université de Paris, CNRS UMR 3569, Viral Genomics and Vaccination Unit, F-75015 Paris, France
}

Correspondence to Nicolas Manel and Nolwenn Jouvenet: nolwenn.jouvenet@pasteur.fr (N. Jouvenet) @lab_jouvenet (N. Jouvenet); @NicolasManellab (N. Manel)

https://doi.org/10.1016/j.jmb.2021.167277

Edited by Alex Compton

\begin{abstract}
Establishment of the interferon (IFN)-mediated antiviral state provides a crucial initial line of defense against viral infection. Numerous genes that contribute to this antiviral state remain to be identified. Using a loss-of-function strategy, we screened an original library of 1156 siRNAs targeting 386 individual curated human genes in stimulated microglial cells infected with Zika virus (ZIKV), an emerging RNA virus that belongs to the flavivirus genus. The screen recovered twenty-one potential host proteins that modulate ZIKV replication in an IFN-dependent manner, including the previously known IFITM3 and LY6E. Further characterization contributed to delineate the spectrum of action of these genes towards other pathogenic RNA viruses, including Hepatitis $C$ virus and SARS-CoV-2. Our data revealed that APOL3 acts as a proviral factor for ZIKV and several other related and unrelated RNA viruses. In addition, we showed that MTA2, a chromatin remodeling factor, possesses potent flavivirus-specific antiviral functions induced by IFN. Our work identified previously unrecognized genes that modulate the replication of RNA viruses in an IFN-dependent manner, opening new perspectives to target weakness points in the life cycle of these viruses.

(c) 2021 The Author(s). Published by Elsevier Ltd. This is an open access article under the CC BY-NC-ND license (http://creativecommons.org/licenses/by-nc-nd/4.0/).
\end{abstract}

\section{Introduction}

Viruses are high on the list of global public health concerns, as illustrated by recent epidemics caused by Ebola, Zika (ZIKV) and Nipah viruses, as well as by the ongoing SARS-CoV-2 pandemic. The vast majority of these emerging RNA viruses have zoonotic origins and have recently crossed host species barrier. ${ }^{1}$ In order to establish itself in a host species, one of the first and most restrictive barriers that a virus needs to overcome is the antiviral innate immune system. This response has evolved to rapidly control viral replication and limit virus spread via detection of viral nucleic acids by pathogen 
recognition receptors (PRRs). ${ }^{2}$ These PRRs can be membrane-associated, such as Toll-like receptor (TLRs), or cytosolic, such as retinoic acid inducible gene I (RIG-I)-like receptor (RLRs). Upon binding to viral nucleic acids, these PRRs interact with adaptor proteins and recruit signaling complexes. These events lead to the expression of type I and type III interferons (IFNs). Secreted type I and type III IFNs will then bind to their heterodimeric receptor, IFNAR1/IFNAR2 and IFN- $\lambda$ R1/IL-10R2, respectively, and activate the canonical JAK/STAT pathway in infected and surrounding cells. ${ }^{3}$ This activation triggers the assembly of the interferonstimulated gene 3 (ISGF3) complex (composed of STAT1, STAT2 and IRF-9 proteins), which subsequently induces the expression of up to approximately 2000 IFN-stimulated genes (ISGs), ${ }^{4,5}$ effectively establishing the antiviral state. ISGs comprise a core of genes that are induced at high levels essentially in all cell types, as well as celltype specific genes that are the result of transcriptome remodeling, ${ }^{6,7}$ highlighting the importance of studying ISGs in relevant cell types. Some of these ISGs have been well characterized. They directly block the viral life cycle by targeting specific stages of virus replication, including entry into host cells, protein translation, replication or assembly of new viral particles. ${ }^{4,8}$ Some ISGs are specific to a virus or a viral family, while others are broad-spectrum. They can also be negative or positive regulators of IFN signaling and thus facilitate, or not, the return to cellular homeostasis. However, the contribution of most ISGs to the antiviral state remains poorly understood.

Over the last decades, flaviviruses have provided some of the most important examples of emerging or resurging diseases, including ZIKV, dengue virus (DENV), Yellow fever virus (YFV) and West Nile virus (WNV). ${ }^{9}$ These flaviviruses are arthropod-borne viruses transmitted to vertebrate hosts by mosquitoes. They cause a spectrum of potentially severe diseases including hepatitis, vascular shock syndrome, encephalitis, acute flaccid paralysis, congenital abnormalities and fetal death. ${ }^{9}$ They are now globally distributed and infect up to 400 million people annually. Lesser-known flaviviruses are beginning to emerge in different parts of the world, as illustrated by the recent incursion of Usutu virus (USUV) in the Mediterranean basin. ${ }^{10}$

ZIKV was isolated in 1947 in a macaque from the Zika Forest in Uganda. ${ }^{11}$ For decades, it remained in Africa and Asia where it sparked local epidemics characterized by a mild self-limiting disease in humans. In recent years, Asian lineage viruses have emerged as a global public health threat with widespread epidemics in the Pacific Islands and Americas, where over 35 countries have reported local transmission in 2016. An estimated 1 million individuals were affected by ZIKV in Brazil in 2015-16. Infection by ZIKV has been linked to several neurological disorders, including GuillainBarré syndrome (GBS), meningoencephalitis, myelitis and congenital microcephaly, fetal demise and abortion. ${ }^{11}$ Children exposed to ZIKV in utero may present neurocognitive deficits, regardless of head size at birth. ZIKV infection is now identified as a sexually-transmitted illness as well. ${ }^{12}$ As all flaviviruses, ZIKV is an enveloped virus containing a positive-stranded RNA genome of $\sim 11 \mathrm{~kb}$. Upon viral entry, the viral genome is released and translated by the host cell machinery into a large polyprotein precursor. The latter is processed by host and viral proteases into three structural proteins, including $\mathrm{C}$ (core), prM (precursor of the $M$ protein) and $E$ (envelope) glycoproteins, and seven non-structural proteins (NS) called NS1, NS2A, NS2B, NS3, NS4A, NS4B and NS5. ${ }^{9}$ The structural proteins constitute the viral particle, while NS proteins coordinate RNA replication, viral assembly and modulate innate immune responses.

The importance of IFN signaling in mediating host restriction of ZIKV is illustrated by the severe pathogenicity in IFNAR1 $1^{-1-}$ and STAT2 ${ }^{-1-}$ but not in immunocompetent mice. ${ }^{13-15}$ Moreover, the Zika strain that is responsible for the recent epidemics has accumulated mutations that increase neurovirulence via the ability to evade the immune response. ${ }^{16}$ Microglial cells, which are the resident macrophages of the brain, represent ZIKV targets and potential reservoirs for viral persistence. ${ }^{17}$ Moreover, they may play a role in ZIKV transmission from mother to fetal brain ${ }^{18}$ and affect the proliferation and differentiation of neuronal progenitor cells. ${ }^{19}$ In order to comprehend the molecular bases behind the efficacy of the IFN response to ZIKV replication, we set up a high throughput assay to identify genes that are modulating viral replication in human microglial cells (HMC3) stimulated with IFN.

\section{Results}

\section{A loss-of-function screen identified genes modulating ZIKV replication in IFN-stimulated human microglial cells}

We selected 386 human genes based on a gene signature defined by clustering and correlation of expression with MX1, a well-described ISG, in a dataset of gene expression in primary human $\mathrm{CD}^{+} \mathrm{T}$ cells (Cerboni et al., in preparation) (Table S1). 36\% of the identified genes overlapped with previous ISG libraries, ${ }^{20,21}$ ensuring that the screen would be simultaneously capable of identifying expected hits and new genes of interest.

Pilot experiments were conducted in human microglial cells (HMC3) to optimize IFNa2 concentration and viral multiplicity of infection (MOI) (Figure S1(A)). SiRNAs targeting IFNAR1 
and IFNAR2 were used as positive controls. SiRNAs against IFITM3, an ISG known to potently inhibit ZIKV replication in several human cell lines and primary fibroblasts, ${ }^{23,24}$ were used as additional positive controls in these experiments (Figure S1 (A)). In cells transfected with siRNAs targeting IFNAR1, the level of infection was almost rescued to the level of non-treated cells, in contrast to cells transfected with non-targeting siRNAs (Figure S1 (A)). In cells silenced for IFITM3 expression, the number of infected cells was partly restored to the level of non-treated cells (Figure S1(A)), which was expected since the antiviral state requires the concerted action of numerous ISGs. ${ }^{20}$

To conduct the screens, HMC3 cells were transfected with individual siRNA 6 hours postseeding, treated with IFN $\alpha 2$ at day 2 , infected with ZIKV at day 3 and fixed 24 hours later (Figure 1 (A)). Percentages of infected cells were determined by confocal analysis by measuring the number of cells expressing the viral $E$ protein (Figure 1(A)). Quality control, performed as described in the method section, confirmed siRNA transfection efficiency by using siRNAs against KIF11, a protein essential for cell survival, ${ }^{22}$ and the efficacy of positive IFNAR1- and IFNAR2siRNA targeting controls (Figure S1B-E). The screen was conducted in duplicate and analyzed using 2 approaches. The first approach took into consideration the intensity of the $\mathrm{E}$ signal per cell while the second one identified infected cells based on the $\mathrm{E}$ presence, independently of the intensity of the signal. The 2 analysis identified similar number of infected cells (Figure S1(F)). Results were expressed as robust Z-scores for each siRNA (Figure $1(B, C))$. Genes were defined as hits when at least two over three of their robust $Z$ scores had an absolute value superior to 2 in the two replicates, in at least one of the analysis. The screen identified 9 antiviral genes and 12 proviral ones (Figure 1(D)). Some hits were previously described as modulators of ZIKV replication, such as IFITM3 ${ }^{23,24}$ and LY6E, ${ }^{25}$ thus validating our loss-of-function screening approach. These twenty-one hits were selected for further validation.

IFNa2-treated HMC3 cells were transfected with pool of 3 siRNAs against each candidate, and not by individual ones as in the primary screening, to overcome potential off-target effect and a limited efficacy of transcript knockdown. Twenty-four hours post-ZIKV infection, intracellular viral RNA production was quantified by RT-qPCR and the number of cells positive for the viral protein $E$ was assessed by flow cytometry analysis. The same samples were used to assess the efficacy of the siRNAs. RT-qPCR analyses revealed that 15 out of the 21 siRNA pools were reducing the expression of their respective targets in IFNtreated cells (Figure S1(G)). mRNAs levels of C1R, XCL1, GBP3, NADK, C22orf39 and RUBCN were below the detection limit in IFN $\alpha 2$-treated
HMC3 (Figure S1(G)). These genes were thus excluded from further anaysis. Reduced expression of IRF9, IFITM3, MTA2 and GPD2 significantly enhanced both viral RNA yield and the number of infected cells as compared to IFN $\alpha 2$-treated cells transfected with control siRNAs (Figure 1(E and $F)$ ). Both IRF9, which belongs to the ISGF3 complex ${ }^{26}$, and IFITM3 ${ }^{27}$ are well-known broadly-acting IFN effectors. The activities of MTA2 have, so far, not been linked to antiviral immunity. MTA2 is a component of the nucleosome remodeling deacetylase NuRD complex, which exhibits ATP-dependent chromatin remodeling activity in addition to histone deacetylase activity. ${ }^{28}$ Ten times more viral RNA copies were recovered in cells silenced for MTA2 expression than in control cells (Figure $1(E)$ ) and four times more cells were positive for the viral $E$ protein (Figure $1(F))$. These effects were comparable to the ones induced by IFNAR1 silencing (Figure 1(E and $F)$ ). Reducing the expression of the 3 other antiviral candidates (PXK, NMI and IFI16) had no significant effect on ZIKV replication in these assays (Figure $1(E$ and $F)$ ), suggesting that they may be false positive candidates. Reducing the expression of LY6E, ISG15 and APOL3 significantly decreased both viral RNA production and the number of cells positive for the $E$ protein (Figure 1(G and $\mathrm{H})$ ), validating the pro-viral activities of these 3 candidates. The pro-viral function of USP18 and NAPA were also validated since reducing their expression led to a significant reduction of the number of infected cells as compared to control cells (Figure 1 (H)). Reduced expression of ISG20 or CCND3 had no significant effect on ZIKV replication (Figure 1(G and $\mathrm{H}$ )). IRF2, which was identified as a pro-viral hit by the screen, behaved like an antiviral gene in the validation experiments (Figure 1(G)). Together, these experiments validated the antiviral function of IRF9, IFITM3, MTA2 and GPD2 and the proviral function of LY6E, USP18, ISG15, APOL3 and NAPA in IFNa2-treated HMC3 cells infected with ZIKV.

\section{Effect of a selection of candidate genes on HCV and SARS-CoV-2 replication}

We next explored the ability of 10 candidate genes (IRF9, IFITM3, MTA2, GPD2, LY6E, USP18, ISG15, APOL3, GBP3 and NAPA) to modulate the replication of two other pathogenic RNA viruses: Hepatitis $\mathrm{C}$ virus (HCV) and Severe Acute Respiratory Syndrome Coronavirus 2 (SARS-CoV-2), which are, respectively, related and unrelated to ZIKV. HCV, which is a member of the Hepacivirus genus within the Flaviviridae family, has a tropism for hepatocytes. SARS-CoV2 belongs to the Coronaviridae family and has a tropism for pneumocytes and enterocytes.

$\mathrm{HCV}$ infections were conducted in hepatoma Huh-7.5 cells, which support well viral replication. $^{29}$ Huh-7.5 cells are unable to induce 
A
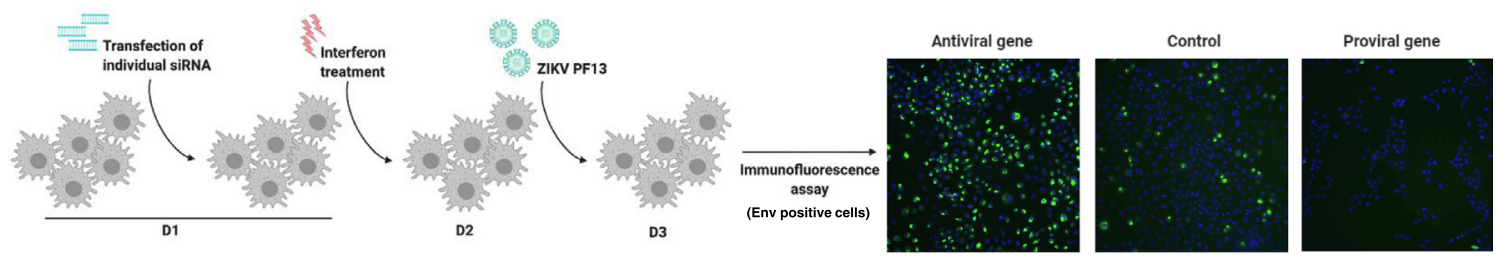

B
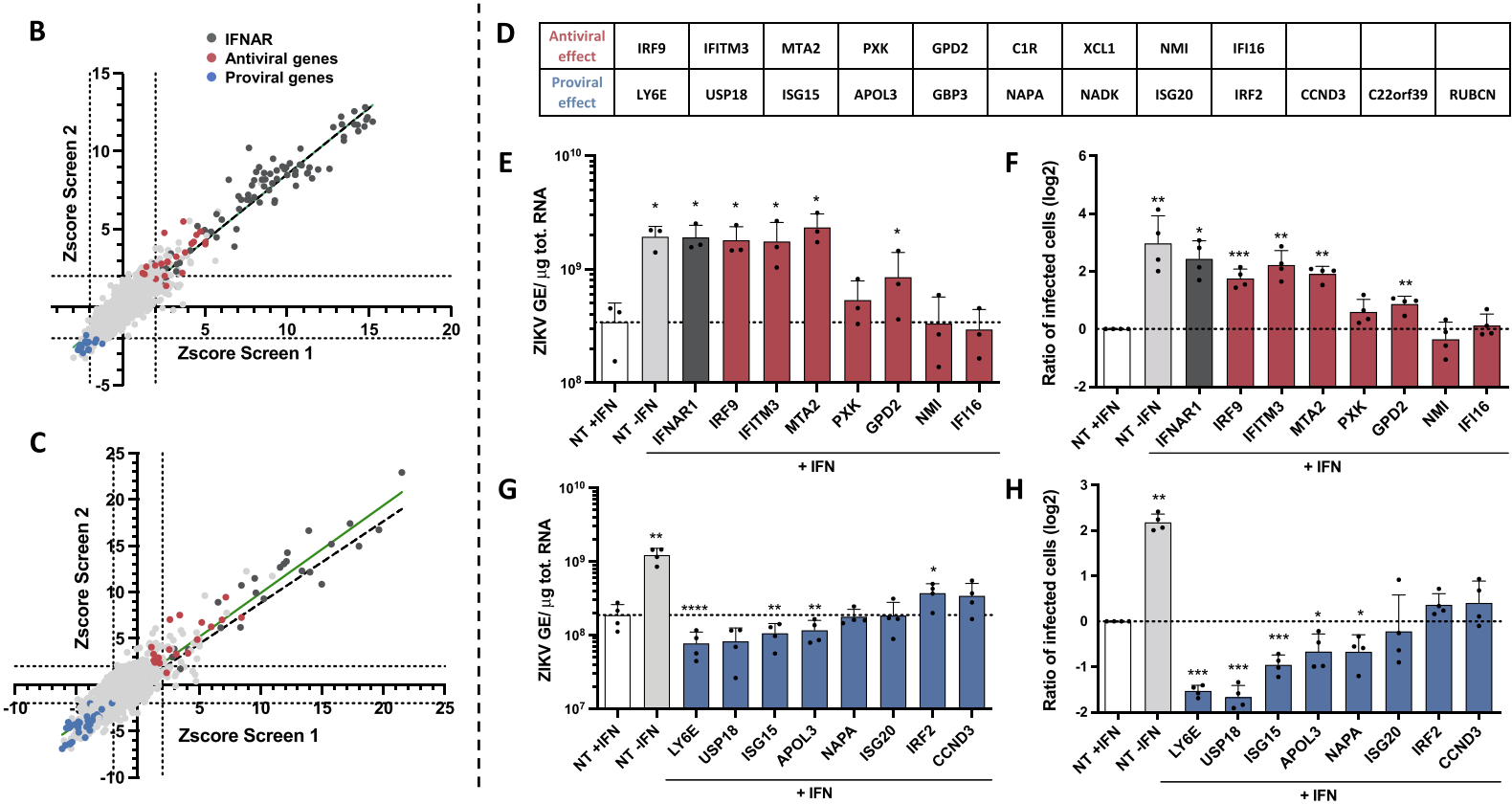

Figure 1. A loss of function screen identified genes modulating ZIKV replication in IFN-stimulated human microglial cells. (A) Scheme summarizing the screen conditions. (B, C) Scatter plots showing the rZ-score obtained in the 1st $(B)$ and second analysis $(C)$ of the 2 screens. The green line represents the linear regression, as compared to the expected perfect correlation (dotted black line). Antiviral and proviral hits are depicted in red and blue, respectively. (D) List of the antiviral and proviral hits as identified by the 2 analysis of the 2 screens. Assessment of the antiviral $(E, F)$ and proviral $(G, H)$ activities of some hits. HMC3 cells were transfected with either pool of 3 siRNAs against the indicated candidate gene or non-targeting (NT) siRNAs, treated with IFN $\alpha 2$ (200 U/mL) for $24 \mathrm{hours}$ and infected with ZIKV (at an MOI of 5 PFU/cell) for 24 hours. Control cells transfected with NT siRNA in the absence of IFN $\alpha 2$ treatment (NT-IFN) are included. (E, G) Cell-associated viral RNA was quantified by RT-qPCR and expressed as genome equivalents $(\mathrm{GE})$ per $\mu \mathrm{g}$ of total cellular RNA. $(\mathrm{F}, \mathrm{H})$ The number of cells positive for viral protein $E$ was assessed by flow cytometry and are expressed relatively to the NT + IFN control of each experiment. Data are means $\pm \mathrm{SD}$ of three or four independent experiments, ${ }^{\star} p<0.05,{ }^{\star *} p<0.01,{ }^{\star \star *} p<0.001$, paired $t$-tests.

IFN expression since they express an inactive form of RIG-1 ${ }^{30}$ but they possess an intact JAK/STAT pathway and do thus respond to IFN treatment. ${ }^{31}$ RT-qPCR analyses revealed that 8 out 10 siRNA pools efficiently reduced the expression of their respective targets in stimulated Huh-7.5 cells (Figure S2(A)). Since LY6E and APOL3 mRNA levels were under the limit of detection of the assays in IFNa2-treated Huh-7.5 cells (Figure S2(A)), they were excluded from further analysis. As expected, reduced expression of IFNAR and IRF9 significantly enhanced HCV RNA yield and the production of infectious particles in IFN $\alpha 2$-treated Huh-7.5 cells, as compared to control cells (Figure 2(A, B)).
Reduced expression of IFITM3, MTA2 or GPD2, which significantly enhanced ZIKV replication in HCM3 cells (Figure $1(E, F)$ ), did not affect HCV RNA production (Figure 2(A)). However, surprisingly, their reduced expression triggered a significant decrease in the release of infectious HCV particles as compared to control cells (Figure 2 (B)). This suggests that they might favor a late stage of HCV replication cycle. RT-qPCR analysis and titration assays identified USP18 and ISG15 as pro-HCV factors in IFN $\alpha 2$-treated Huh-7.5 cells (Figure 2(C, D)), validating previous results. ${ }^{32-35}$ Of note, HCV RNA production and infectious particle release were significantly increased in cells with 
A

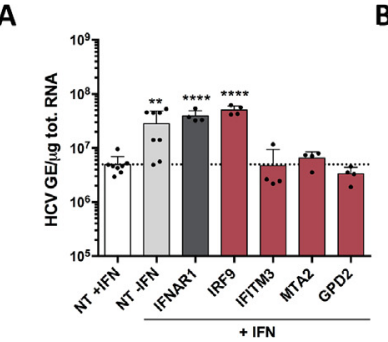

E

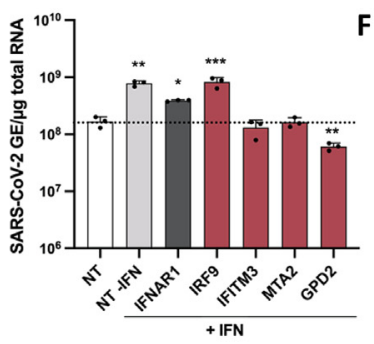

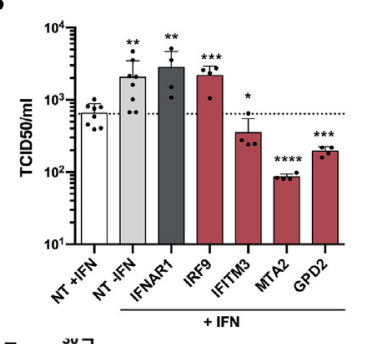

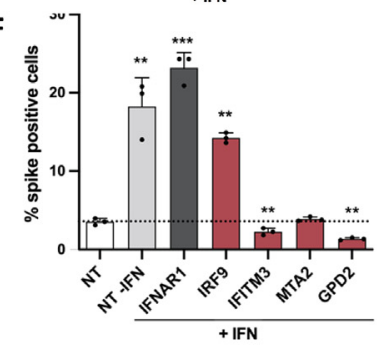

C

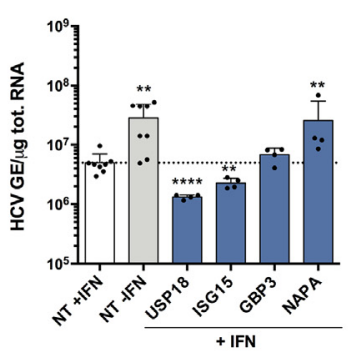

$\mathbf{G}$

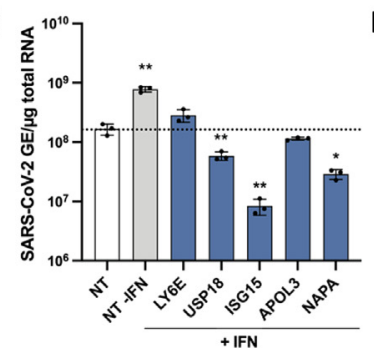

D

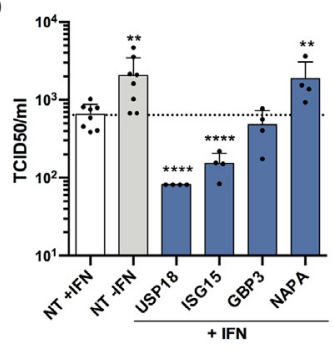

H

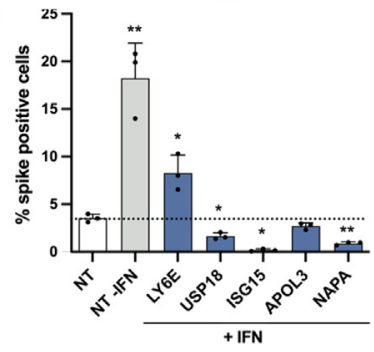

Figure 2. Effect of a selection of candidate genes on HCV and SARS-CoV-2 replication. (A-D) Huh-7.5 cells were transfected with a pool of 3 siRNAs against selected candidates (antiviral and proviral genes, as identified in the ZIKV screen (Figure 1), are in red and blue, respectively) or non-targeting (NT) siRNAs, treated with IFN $\alpha 2$ (200 U/ $\mathrm{mL}$ ) for 24 hours, then infected with $\mathrm{HCV}$ at a MOI of 3 TCID50/cell for 48 hours. (A, C) Cell-associated viral RNA was quantified by RT-qPCR and expressed as genome equivalents (GE) per $\mu \mathrm{g}$ of total cellular RNA. (B, D) Release of infectious HCV particles was determined by TCID50 assays. Data are expressed relatively to the NT + IFN control of each experiment. Plotted values are expressed relative to mean NT + IF across experiements and represent means \pm SD of two independent experiments each in duplicates, ${ }^{\star} p<0.05,{ }^{* \star} p<0.01,{ }^{\star \star \star} p<0.001,{ }^{* \star \star \star} p<0.0001$ paired $t$-tests. $(E-H)$. A549-ACE2 cells were transfected with a pool of 3 siRNAs against selected candidates (antiviral genes in red, proviral genes in blue) or non-targeting (NT) siRNAs, treated with IFN $\alpha 2(200 \mathrm{U} / \mathrm{mL})$ for 24 hours and infected with SARS-CoV-2 at a MOI of 2 for 24 hours. (E, G) Cell-associated viral RNA was quantified by RT-qPCR and expressed as genome equivalents (GE) per $\mu \mathrm{g}$ of total cellular RNA. $(F, H)$ The number of cells positive for the viral protein spike (S) was assessed by flow cytometry Data are expressed relatively to the NT + IFN control of each experiment. Data are means \pm SD of triplicates of one experiment, ${ }^{\star} p<0.05,{ }^{\star \star} p<0.01,{ }^{\star \star \star} p<0.001$, paired $t$-tests.

reduced NAPA levels (Figure 2(C, D)), suggesting that NAPA may exert an antiviral effect on HCV, while it was not the case for ZIKV (Figure 1(G, H)).

SARS-CoV-2 replication was assessed in A549 alveolar epithelial cells expressing the viral receptor ACE2 (A549-ACE2) by RT-qPCR and flow cytometry analysis using an antibody against the viral protein Spike (S). Of note, silencing GBP3 in A549-ACE2 cells triggered cell death. RT-qPCR analyses showed that all siRNA pools were reducing the expression of their respective targets in stimulated A549-ACE2 cells (Figure S2 (B)). These analyses revealed the ability of IRF9 to act as an anti-SARS-CoV-2 gene (Figure 2(E, F)). Unexpectedly, GPD2 and IFITM3, which we identified as genes possessing anti-ZIKV activities (Figure 1), tended to behave like pro-viral genes in the context of SARS-CoV-2 infection (Figure 2(E, F)). Viral RNA yields decreased significantly in cells silenced for USP18, ISG15 and NAPA expression, as compared to cells transfected with control siRNAs (Figure 2(G)), suggesting that these 3 genes promote viral replication in stimulated A549-ACE2 cells. By contrast to what we observed in ZIKV infected cells (Figure 1(G, $H)$ ), LY6E seemed to restrict SARS-CoV-2
(Figure 2(H)). These results are in accordance with a recent report. ${ }^{36}$ Reducing MTA2 or APOL3 expression did not affect SARS-CoV-2 replication.

These results suggest that some genes are broadly-acting IFN effectors, such as IRF9 and ISG15. Other genes appeared to have evolve modulatory function toward a specific viral family or genus, such as APOL3 and MTA2. Finally, some genes, including LY6E, IFITM3 and GPD2, exhibited opposite modulatory functions towards different viral species.

\section{ZIKV, DENV-2, WNV, VSV and MeV, but not MVA, require the expression of APOL3 for optimal replication in IFN-treated cells}

LY6E, ISG15 and APOL3 exhibited significant pro-ZIKV activities in stimulated cells, as measured by cell-associated viral RNA levels (Figure $1(G)$ ) and percentage of E-positive cells (Figure $1(\mathrm{H})$ ). Among these 3 genes, APOL3 is the least described and was thus selected for further characterization. APOL3 is one of the 6 members of the apolipoprotein L gene family. Apolipoproteins are typically associated with the transport of lipids in the organism and were 
originally described as members of the high-density lipoprotein family, which are involved in cholesterol transport. $^{37}$ In human cells, the expression of the 6 members of the APOL gene family are up-regulated by multiple pro-inflammatory signaling molecules, including IFNs and TNF $\alpha^{37,38}$ These regulations suggest a link between APOL proteins and the innate immune system. siRNA targeting APOL2, APOL3, APOL4, APOL5 and APOL6 were present in our library (Table S1). Among these 5 APOLs, only APOL3 was identified as a facilitator of ZIKV infection by our screen (Figure 1). We decided to test the ability of APOL1 to modulate ZIKV replication since it was previously identified in a highthroughput overexpression screen as an ISG able to increase YFV infection in STAT1 ${ }^{-1-}$ fibroblasts and Huh-7cells. ${ }^{20}$

Analysis of mRNA levels of APOL1 and APOL3 revealed that the genes were upregulated by IFNa2 treatment in HMC3 cells (Figure 3(A)). Both genes thus qualify as genuine ISGs in these cells. The implication of APOL1 and APOL3 in ZIKV replication was investigated using loss-of-function approaches. siRNA-silencing reduced the levels of APOL1 and APOL3 mRNAs by 80\% and 85\%, respectively, when compared to cells expressing scrambled control siRNAs (Figure 3(B)). USP18, which is known to negatively regulates the JAKSTAT pathway, and, as such, is a broad-spectrum pro-viral factor, ${ }^{39}$ was identified during our screen as a pro-ZIKV candidate in HMC3 cells (Figure 1 (D)). Since its pro-ZIKV function was validated in our system (Figure $1(\mathrm{H})$ ), siRNAs specific for USP18 were used as positive controls. siRNAsilencing reduced the abundance of USP18 mRNAs by $\sim 80 \%$ when compared to cells expressing control siRNAs (Figure $3(B)$ ). Viral replication was assessed by flow cytometry by measuring the number of cells positive for the viral protein $E$ in cells silenced for APOL1, APOL3 or USP18, treated or not with IFNa2. Higher MOls were used in IFNa2treated cells than in untreated ones to compensate for its antiviral effects. As expected (Figure 1(H)), reduced expression of USP18 significantly decreased the number of IFN-treated cells positive for the viral protein $\mathrm{E}$, as compared to cells transfected with control siRNAs (Figure $3(\mathrm{C})$ ). Extinction of APOL1 and APOL3 resulted in a modest, but reproducible, decrease in the number of E-positive HMC3 cells pre-treated with IFN $\alpha 2$ (Figure 3(C)). A pro-viral effect of APOL1 was also observed in unstimulated cells (Figure $3(\mathrm{C})$ ). The efficacy of the siRNAs against APOL1 and USP18 were further validated by Western Blot analysis (Figure 3(D)). APOL3 levels in cell lysates could not be assessed due to the lack of available antibodies. Levels of expression of the viral proteins NS5 and E were slightly decreased in IFNa2-cells expressing reduced levels of APOL1 or APOL3, compared to control cells (Figure $3(D)$ ). Together, these results suggest that ZIKV requires the expression of APOL1 and APOL3 for optimal replication in HMC3 cells. By contrast to APOL1, the pro-viral action of APOL3 was dependent on IFN $\alpha 2$-treatment.

To ensure that the APOL1- and APOL3-mediated modulation of viral replication was not restricted to HMC3 cells, experiments were performed in human podocytes, which are physiologically relevant for ZIKV infection since viral RNA was detected in kidneys of infected patients. ${ }^{40}$ Assessing the mRNA abundance of APOL1 and APOL3 by RT-qPCR analysis of podocytes treated or not with IFN $\alpha 2$ revealed that both genes qualify as ISGs in podocytes (Figure 3(E)). siRNA-mediated silencing of APOL1, APOL3 and USP18 was efficient in podocytes (Figure 3(F)). Reduced expression of APOL1 or APOL3 resulted in a significant decrease of the percentage of infected cells in IFNa2-treated podocytes, but not in unstimulated cells (Figure 3 (G)). Western blot analysis performed in IFNa2treated podocytes revealed that cells expressing little APOL1/3 were producing less viral proteins than controls cells (Figure $3(\mathrm{H})$ ), confirming the pro-ZIKV activity of the two APOLs. These data revealed that APOL3 and APOL1 facilitate the replication of ZIKV in podocytes treated with IFN $\alpha 2$.

We tested whether APOL1 and APOL3 were active against DENV-2 or WNV, which are flaviviruses closely related to ZIKV. HMC3 cells were treated or not with IFN $\alpha 2$ and the MOls were adapted to the IFN $\alpha 2$ treatment. Flow cytometry analysis using anti-E antibodies revealed that both DENV-2 and WNV replication were significantly decreased in IFNa2-treated cells silenced for APOL1 or APOL3 expression (Figure 3(I)). Reducing APOL1 and APOL3 expression in nontreated cells also significantly reduced WNV replication (Figure $3(\mathrm{I})$ ). Thus, APOL $1 / 3$ may well have flavivirus-specific proviral activities since they seems to contribute to ZIKV, WNV and DENV replication (Figure $3(\mathrm{C}, \mathrm{D}, \mathrm{G}, \mathrm{H}$ and I)) but not to SARS-CoV-2 replication (Figure $2(\mathrm{G}, \mathrm{H})$ ). To further delineate the spectrum of proviral action of these two genes, we tested the effect of APOL $1 / 3$ silencing on the replication of Vesicular Stomatitis virus (VSV) and Measles virus (MeV), which are negative-strand RNA viruses belonging to the Rhabdoviridae and Paramyxoviridae families, respectively. Experiments were performed with a MeV strain modified to express GFP. ${ }^{41}$ We also included in the analysis Modified Vaccinia Ankara virus (MVA), a DNA virus belonging to the poxviridae family, that was engineered to express GFP (MVA-GFP). Flow cytometry analysis using an antibody against the viral protein $G$ revealed that VSV was highly dependent on APOL1 and APOL3 expression for efficient replication in IFNa2-treated HMC3 cells (Figure 3(I)). Optimal replication of MeV-GFP in stimulated HMC3 cells also required APOL1 and APOL3 expression (Figure 3(I)). APOL1 proviral activity was also observed in unstimulated cells (Figure $3(\mathrm{I})$ ). By contrast, 

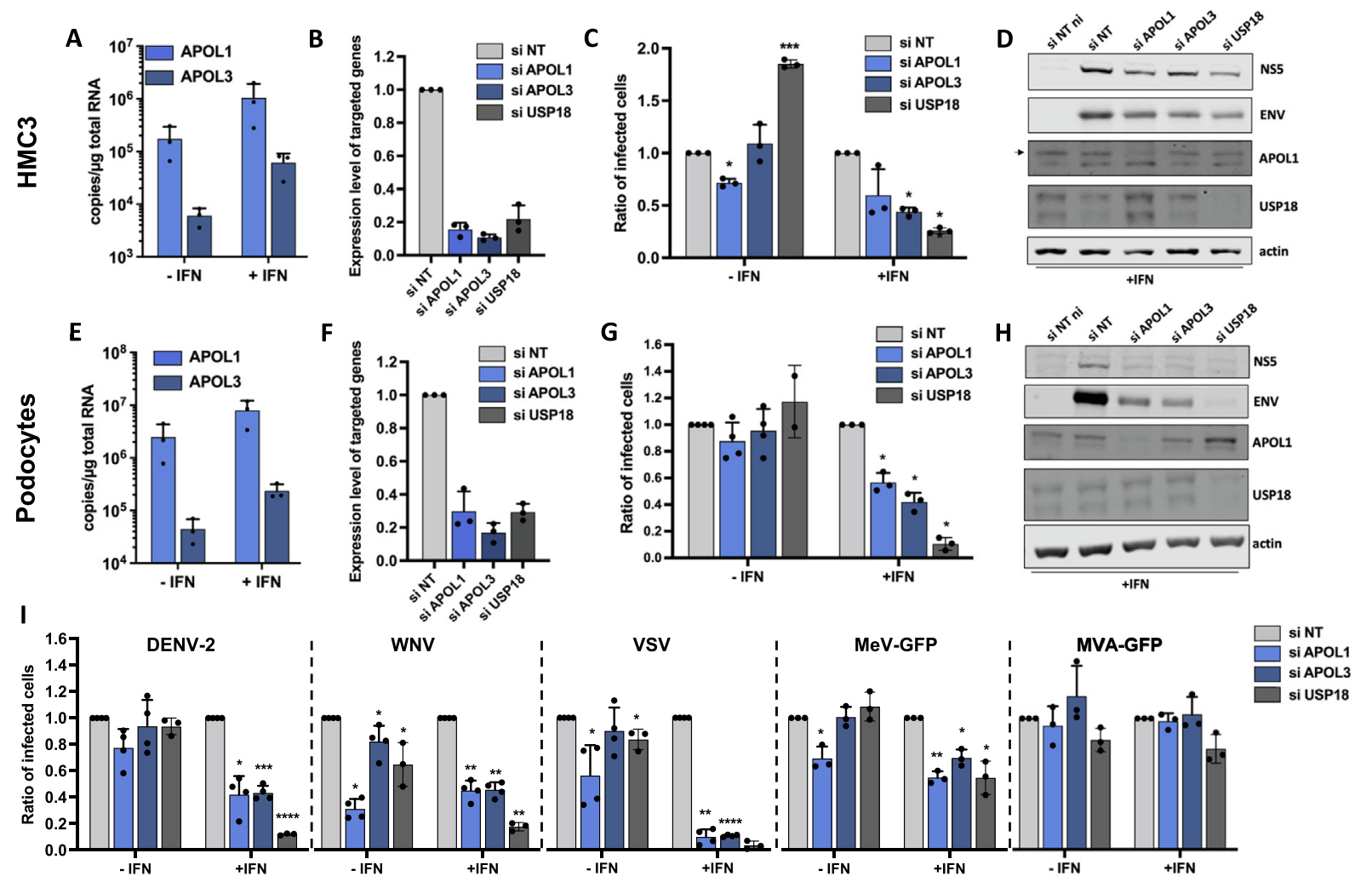

Figure 3. Effect of reduced expression of APOL1 and APOL3 on the replication of a panel of viruses in HMC3 cells and podocytes. (A, E) APOL1 mRNA and APOL3 mRNA abundance were quantified by RT-qPCR analysis in HMC3 cells or podocytes treated or not with IFN $22(200 \mathrm{U} / \mathrm{mL})$ for 24 hours and expressed as copy numbers per $\mu \mathrm{g}$ of total cellular RNA. HMC3 cells $(B)$ or podocytes $(F)$ were transfected with pool of 3 siRNAs targeting APOL1, APOL3 and USP18 mRNAs or with non-targeting (NT) control siRNAs. The relative amounts of APOL1, APOL3 and USP18 mRNAs were determined by RT-qPCR analysis and were normalized to that of GAPDH mRNA. They are expressed as compared to abundance relative to cells transfected with control NT siRNAs. HMC3 cells $(C)$ or podocytes $(G)$ were transfected with the indicated siRNAs, treated, or not, with IFNa2 (200 U/mL) for 24 hours, and infected with ZIKV for 24 hours. HMC3 cells were infected at a MOI of 2 and podocytes at a MOI of 1 . The percentages of cells that were positive for the viral $\mathrm{E}$ proteins were determined by flow cytometric analysis. Data are expressed relatively to the siRNA NT control of each experiment. HMC3 cells (D) or podocytes $(\mathrm{H})$ were treated with IFN $\alpha 2(200 \mathrm{U} / \mathrm{mL})$, transfected with the indicated siRNAs pools and subjected to Western blotting analysis with antibodies against the indicated proteins. (I) HMC3 cells were transfected with the indicated siRNAs pools, treated with IFNa2 $(200 \mathrm{U} / \mathrm{mL})$ for 24 hours and infected with the indicated viruses for 18 to 24 hours, at the MOI indicated in the MM section. The percentages of the cells positive for viral proteins or GFP were determined by flow cytometric analysis. Data are means \pm SD of three or four independent experiments, ${ }^{\star} p<0.05,{ }^{\star \star} p<0.01,{ }^{\star \star *} p<0.001$, paired $t$ tests.

MVA-GFP replication was not affected by reduced expression of either APOL1 or APOL3 (Figure 3(I)).

Together, these experiments suggest that APOL1 and APOL3 could favor a replication process shared by ZIKV, DENV-2, WNV, VSV and MeV. Unlike APOL1 in HMC3 cells, APOL3 pro-viral activities were dependent on IFN-treatment.

\section{APOL1 and APOL3 likely promote viral replication independently of their interaction with phosphoinositides}

Recent data revealed that APOL1 and APOL3 play a role in lipid metabolism in podocytes and, more specifically, in the regulation of the production of phosphatidylinositol-4-phosphate (PI (4)P), via an indirect interaction with the PI4KB kinase. ${ }^{42} \mathrm{PI}(4) \mathrm{P}$ is involved in Golgi secretory functions by facilitating the recruitment of proteins that promote vesicular transport. ${ }^{43} \mathrm{PI}(4) \mathrm{P}$ is also essential for the establishment of efficient viral replication via the formation of membranes which serve as platforms for the production of viral RNA. ${ }^{44,45}$ APOL1 and/or APOL3 could thus impact ZIKV replication via their ability to regulate the production of $\mathrm{PI}$ (4)P. To test this hypothesis, we first assessed APOL1 and APOL3 localization in HMC3 cells. In the absence of antibodies for APOL1 and APOL3 
validated for immunofluorescence assays, we investigated the localization of GFP-tagged versions of APOL3 and APOL1 in HMC3 cells, together with markers for the Golgi apparatus (Figure 4(A)), early or late endosomes (Figure S3). APOL1-GFP and GFP-APOL3 localized in closed proximity to the cis-Golgi (Figure 4(A)), where PI(4)P and PI4KB localize, ${ }^{46}$ and not in late nor early endosomes (Figure S3). In line with this, APOL1-GFP and GFPAPOL3 associated with PI4KB in HMC3 cells (Figure 4(B)). Of note, APOL1-GFP was also detected in vesicle-like structures whose identity could not be established (Figure 4(A), white arrow). They may represent lipid droplets or fragmented Golgi. The localization of APOL1-GFP and GFP-APOL3 could not be investigated in ZIKV-infected cells since we observed that transfection rendered cells non-permissive to viral infection.

We then performed experiments with a wellcharacterized PI4KB kinase inhibitor that decreases $\mathrm{PI}(4) \mathrm{P}$ expression. ${ }^{47}$ We first analyzed by immunofluorescence the intensity of the $\mathrm{PI}(4) \mathrm{P}$ signal in cells treated for $24 \mathrm{~h}$ with different concentrations of the drug in $\mathrm{HCM} 3$ cells. The presence of the PI4KB inhibitor triggered a dose-dependent decrease of the $\mathrm{PI}(4) \mathrm{P}$ signal (Figure $4(\mathrm{C})$ ). We then infected cells with ZIKV in the presence of different concentration of the inhibitor. Since the effect of APOL3 on ZIKV replication is dependent on IFN 22 (Figure 3), the analysis was also performed in stimulated cells. Coxsackie B3 virus (CVB3), an enterovirus that replicates in a $\mathrm{PI}(4) \mathrm{P}$-dependent manner, was used as a positive control since its replication is sensitive to the drug. ${ }^{48}$ As negative controls, we used cells infected with WNV, whose replication is not affected by the PI4KB inhibitor. ${ }^{49}$ As previously shown in HeLa cells, ${ }^{48}$ a dosedependent reduction of the number of cells positive for the CVB3 viral protein 1 (VP1) was triggered by the inhibitor treatment (Figure 4(D)). As shown previously in monkey cells, ${ }^{49}$ WNV replication was unaffected by the PI4KB inhibitor in HCM3 cells (Figure 4(D)). ZIKV protein production was not sensitive to the treatment with the PI4KB kinase inhibitor, independently of the presence of IFN $\alpha 2$ (Figure 4(D)). These experiments suggest that the pro-viral activities of APOL1 and APOL3 are not related to their interaction with $\mathrm{PI} 4 \mathrm{~KB}$ or $\mathrm{PI}(4) \mathrm{P}$ in microglial cells.

\section{MTA2 restricts ZIKV replication in IFN $\alpha 2-$ stimulated human cells}

MTA2 was identified in our screen as a gene with potent anti-ZIKV activities (Figure 1). MTA2 shows a very broad expression pattern and is strongly expressed in many tissues. It belongs to the NuRD complex, which establishes transcriptional modulation of a number of target genes in vertebrates, invertebrates and fungi. ${ }^{28}$ Since its function has, so far, not been linked to viral infection, we decided to investigate its potential antiviral activities further. To ensure that the MTA2mediated inhibition of viral replication was not restricted to HMC3 cells, experiments were also performed in Huh-7 hepatoma cells, which are physiologically relevant for flavivirus infection and are thus extensively used in Flaviviridae research. siRNAs targeting IFNAR1 were used as positive controls in these experiments. siRNA-silencing reduced the levels of MTA2 and IFNAR1 mRNAs by at least $80 \%$, when compared to cells expressing scrambled control siRNAs, independently of the stimulation or infection status of HMC3 and Huh-7 cells (Figure 5(A-D)). MTA2 was included in our gene list because its expression clustered with MX1 in T cells (Cerboni et al. in preparation). However, MTA2 mRNA abundance, as measured by RT-qPCR analysis, remained unchanged upon IFN $\alpha 2$ treatment in both cells types (Figure 5(A and $C)$ ), indicating that MTA2 is not an ISG in these cells.

Assessment of viral replication by RT-qPCR revealed that cell-associated viral RNA yields were significantly higher in IFN-treated HMC3 cells silenced for MTA2 expression, as compared to controls cells (Figure $5(E)$ ). This is in line with previous results (Figure $1(E)$ ). Cytometry analysis using anti-E antibodies confirmed that MTA2 antiZIKV activities were dependent on the presence of IFN in HCM3 cells (Figure $5(\mathrm{~F})$ ). Since MTA2 is not an ISG in HMC3 cells (Figure 5(A)), these results suggest that MTA2 may require an active IFN signaling to exert its anti-ZIKV activities in these cells. As in HMC3 cells, reduced expression of MTA2 triggered a significant increase of intracellular viral RNA production in stimulated Huh-7 cells (Figure 5(G)). Reducing MTA2 expression had a more pronounced effect on the percentage of infected cells that reducing IFNAR1 expression in stimulated Huh-7 cells (Figure 5(H)). Albeit to a lesser extent than in stimulated cells, MTA2 anti-ZIKV activity was also observed in nonstimulated Huh-7 cells by flow cytometry and RTqPCR analysis (Figure 5( $\mathrm{G}$ and $\mathrm{H})$ ).

The effect of MTA2 on viral protein production was further assessed by Western blot analysis using anti-E and anti-NS5 antibodies in stimulated and unstimulated HMC3 and Huh-7 cells. These experiments validated further the efficacy of the siRNAs against MTA2 in both cell lines (Figure 5(I and J)). Expression of the viral proteins NS5 and $\mathrm{E}$ were increased in stimulated $\mathrm{HMC} 3$ and Huh-7 cells expressing reduced levels of MTA2 or IFNAR1, as compared to control cells (Figure 5(I and J)). In agreement with the flow cytometry analysis (Figure 5(H)), MTA2 anti-ZIKV activity was less dependent of IFN-treatment in Huh-7 cells than in HMC3 cells (Figure 5(I and J)). As observed in flow cytometry analysis (Figure $5(\mathrm{H})$ ), MTA2 effect on viral protein production was more potent than the one of IFNAR1 in stimulated Huh7 cells (Figure $5(\mathrm{~J})$ ). 
A
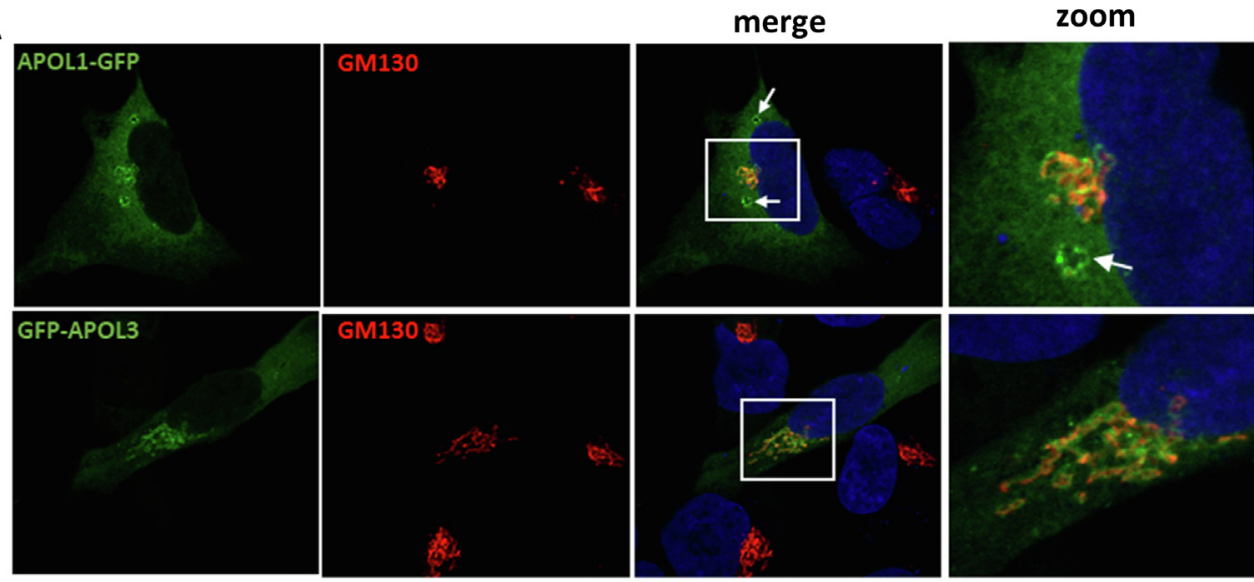

B

merge

zoom
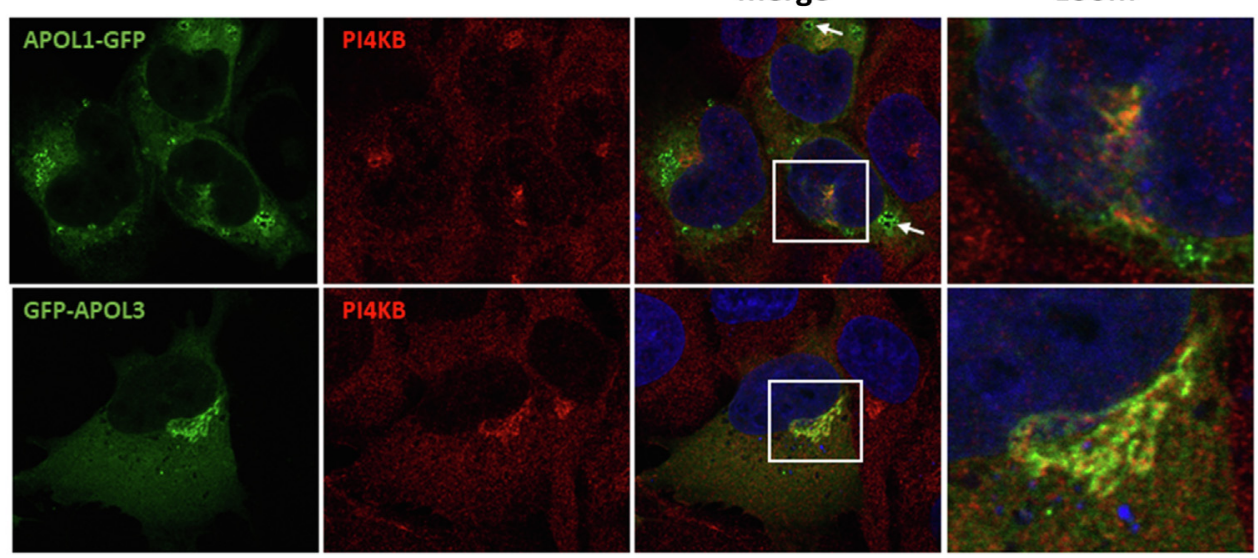

C

DMSO

$10 \mathrm{nM}$

40nM

$160 n M$
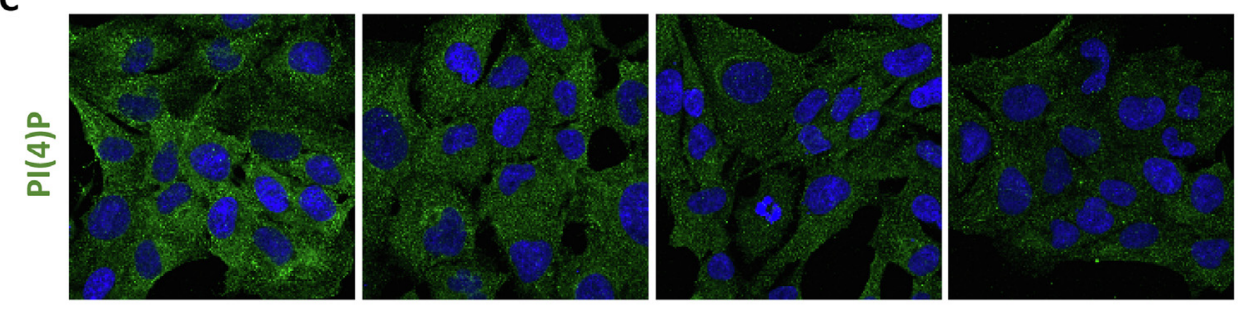

D

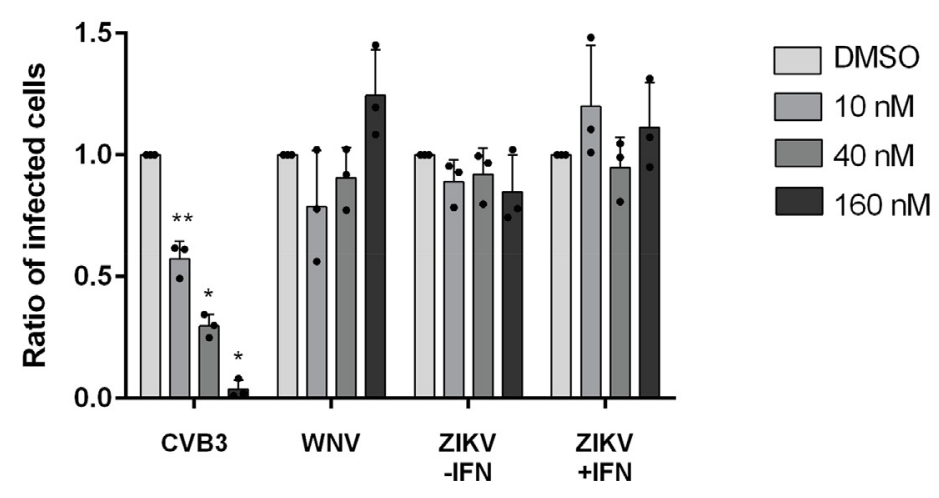


These results represent the first evidence of the ability of MTA2 to restrict the replication of any virus. As a first hint towards deciphering the function of MTA2 in ZIKV infection, we studied its cellular localization by indirect immunofluorescence in uninfected and infected Huh-7 cells. Besides its chromatin-remodeling activities, MTA2 has been reported to associate with the centrosome in non-stimulated human cells. ${ }^{50}$ These experiments revealed that MTA2 localized in the nucleus of non-infected cells (Figure S4). The specificity of MAT2 labeling was confirmed in Huh-7 cells silenced for MTA2 expression (Figure $S 4(A)$ ). No evident change in MTA2 localization was observed in ZIKV-infected cells (Figure S4(B)), which were marked with antibodies specific for the viral NS5 protein, which is known to localize in the nucleus. ${ }^{51,52}$ These results suggest that MTA2-mediated effect on ZIKV replication may be linked to its chromatin-remodeling activity.

\section{MTA2 restricts YFV and WNV replication in IFNa2-stimulated Huh-7 cells}

We tested whether MTA2 was active against WNV and YFV in Huh-7 cells, which are permissive to these 2 flaviviruses. As in previous experiments, higher MOls were used in the presence of IFN $\alpha 2$. Cytometry analysis revealed that MTA2 silencing significantly enhanced the replication of these 2 flaviviruses in an-IFN dependent manner (Figure 6(A and $B)$ ), indicating that MTA2 antiviral activity is broader that ZIKV. We then tested the effect of MTA2 silencing on the replication of VSV and MeV in Huh-7 cells. Reduced expression of MTA2 decreased the number of cells infected with VSV and MeV (Figure 6(C and D)), independently of the IFN stimulation. This is consistent with the pro-HCV activity of MTA2, as measured by titration in stimulated Huh-7.5 cells (Figure 2(B)). MTA2 may thus possesses a flavivirus-specific antiviral function.

\section{Discussion}

Several gain-of-function screens have been performed to identify ISGs that modulate flavivirus infection. Pioneer screens tested the activities of relatively small amounts of ISGs by overexpression. ${ }^{53,54}$ The first comprehensive overexpression screen in which more than 380 ISGs were evaluated for antiviral activity against six viruses, including the Flaviviridae HCV, WNV and YFV, was published in 2011 by Schoggins and collaborators. ${ }^{20}$ To avoid potential physiological irrelevance induced by gene overexpression, we opted for a silencing approach to identify genes that modulate ZIKV replication in an IFN-induced state. We used a siRNA library which was designed in the context of an HIV project. A limitation of our library is that targeted genes were selected based on a transcriptomic analysis of primary $T$ cells stimulated by contacts with activated monocytes (Cerboni et al. in preparation), and not on ZIKV-target cells. Nevertheless, it contains a high fraction of core ISGs that overlaps with previous screens. ${ }^{20,21}$ Furthermore, most arrayed screens designed to identify cellular factors that modulate ZIKV replication, including ours, monitored viral replication after a single round of infection, often by assessing viral protein expression. Therefore, only genes that inhibit early stages of viral replication, up to protein production, can be identified. Quantifying viral titers in supernatants collected from individual wells of the first round of screening should identify genes that affect late stages of viral replication, such as viral assembly, maturation and release, as well as viral infectivity. Alternatively, viral replication could be monitored after several rounds of infection. Nevertheless, despite these two main limitations, our screening strategy identified 21 genes affecting ZIKV replication in IFN-treated microglial cells.

Some hits were previously described as ISGs able to modulate ZIKV replication, such as IFITM3 ${ }^{23,24}$ and LY6E, ${ }^{25}$ thus validating our screening approach. Despite being in our gene list (Table S1), Viperin, IFI6, PARP-12 and C19orf66, which are known to affect ZIKV replication in human cells, ${ }^{55-59}$ were not identified as viral modulators by our strategy. They may have a weaker influence on viral replication in HMC3 cells than in the cells in which their role was previously established. ${ }^{55-59}$ In line with this hypothesis, Viperin restricts the replication of several neurotropic flaviviruses in a cell type-dependent manner. ${ }^{60}$ One can also envisage that the expression levels of Viperin, IFI6, PARP-

Figure Caption Missing

Figure 4. APOL1 and APOL3 promote viral replication independently of their interaction with phosphoinositides. HMC3 cells were transfected with GFP-tagged versions of APOL1 and APOL3. Thirty hours later, they were stained with antibodies recognizing GM130 (A) or PI4KB (B) and with NucBlue to detect nuclei. Images are representative of numerous observations over 2 independent experiments. The white arrow shows an APOL1-GFPpositive vesicle. (C) HCM3 cells were treated with different concentrations of the PI4KB inhibitor and were stained for $\mathrm{PI}(4) \mathrm{P}$. (D) HMC3 cells treated with different doses of PI4KB inhibitor were infected with CVB3, WNV or ZIKV, in the presence or absence of IFN $\alpha 2(200 \mathrm{U} / \mathrm{mL})$. The percentages of the cells positive for viral proteins were determined by flow cytometric analysis. Data are means $\pm \mathrm{SD}$ of three independent experiments, ${ }^{*} p<0.05,{ }^{\star \star} p<0.01,{ }^{\star \star \star} p<0.001$, one-way ANOVA. 


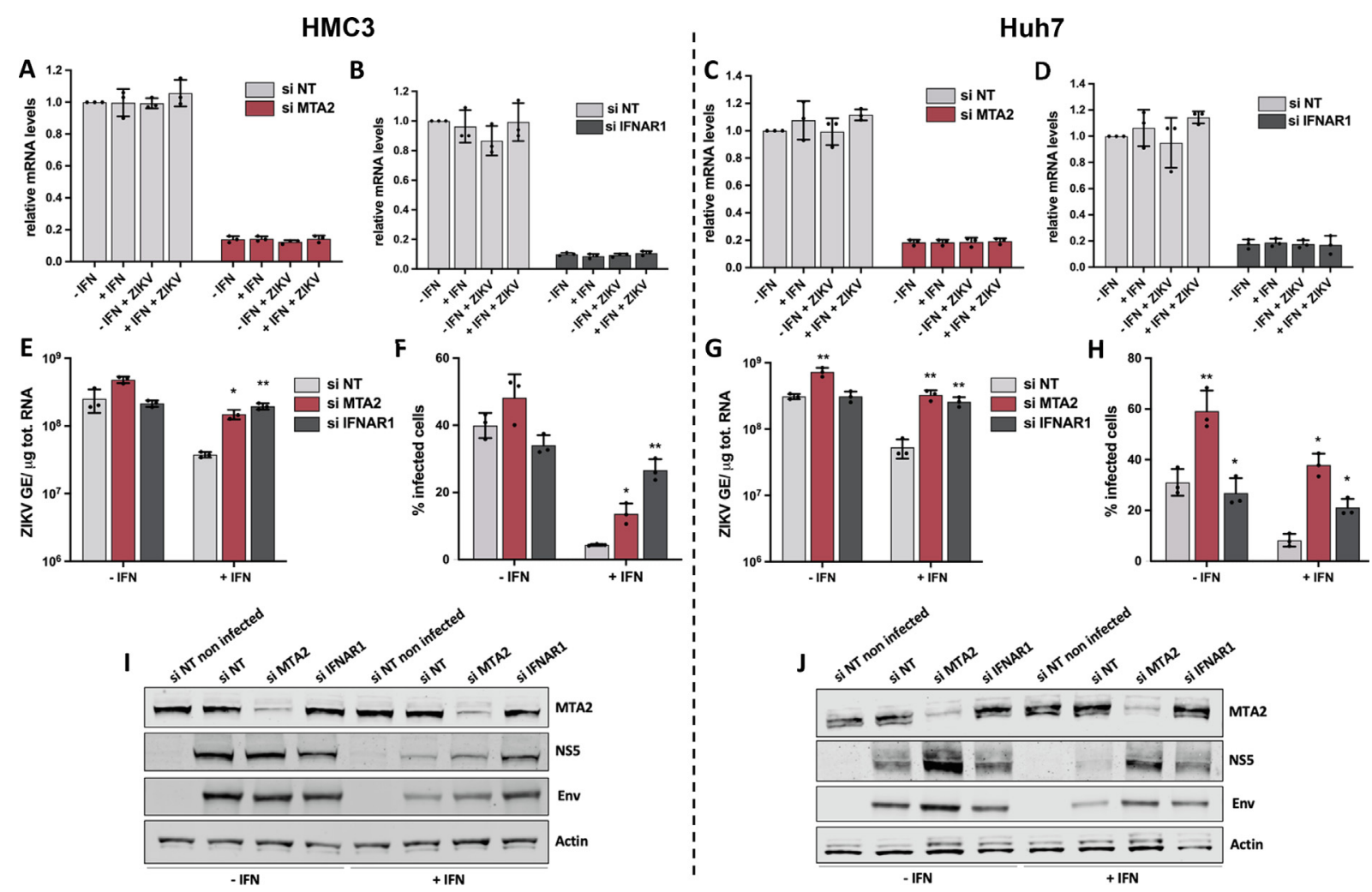

Figure 5. MTA2 restricts ZIKV replication in IFNa2-stimulated cells. HMC3 (A, B, E, F, I) and Huh-7 cells (C, D, $\mathrm{G}, \mathrm{H}, \mathrm{J}$ ) were transfected with pool of 3 siRNAs targeting MTA2 or IFNAR1 mRNAs or non-targeting (NT) control siRNAs, treated or not with IFN $\alpha 2(100 \mathrm{U} / \mathrm{mL})$ for 24 hours, and infected with ZIKV (MOI of 1 for HMC3 cells, MOI of 5 for Huh-7 cells) for 24 hours. (A-D) The relative amounts of MTA2 and IFNAR1 mRNAs were determined by RTqPCR analysis and normalized to that of GAPDH mRNA and siRNA-NT without IFN. (E, G) Cell-associated viral RNA was quantified by RT-qPCR and expressed as genome equivalents (GE) per $\mu g$ of total cellular RNA. (F, H) Number of infected cells was assessed by staining of viral protein $\mathrm{E}$ and flow cytometry analysis. (I, J) Cells were treated with IFN $\alpha 2(200 \mathrm{U} / \mathrm{mL})$ or left untreated, transfected with the indicated siRNAs pools and subjected to Western blotting analysis with antibodies against the indicated proteins. Data are means $\pm S D$ of three independent experiments, ${ }^{\star} p<0.05,{ }^{* \star} p<0.01,{ }^{\star \star *} p<0.001$, paired $t$-tests.
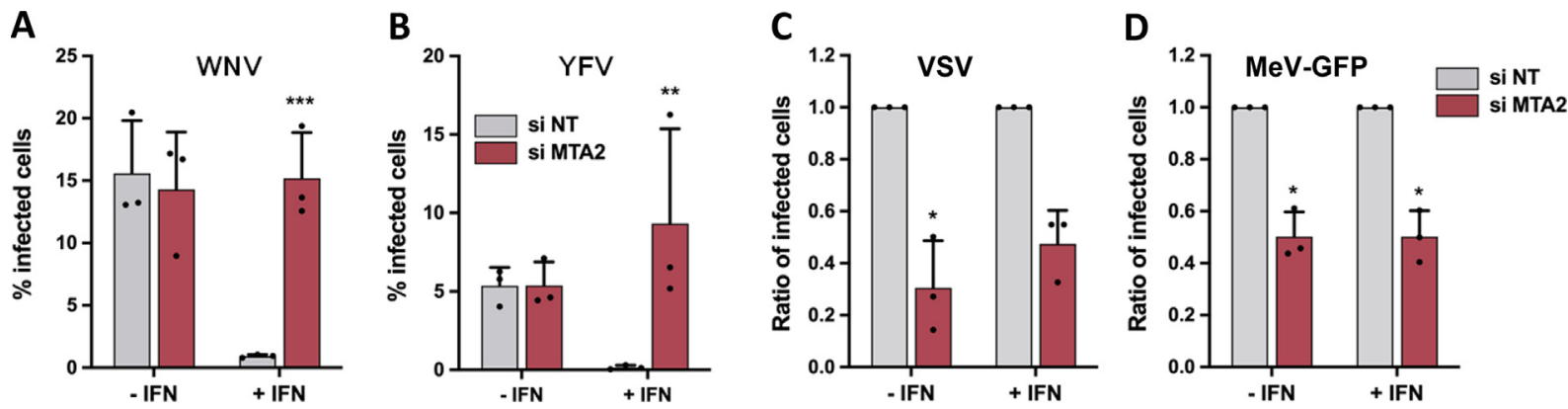

Figure 6. Effect of reduced expression of MTA2 on the replication of YFV, WNV, VSV and MeV-GFP. Huh-7 cells were transfected with the indicated siRNAs pool, treated or not with IFN $\alpha 2(200 \mathrm{U} / \mathrm{mL})$ for 24 hours and infected with WNV (A) or YFV (B) for 24 hours, at the MOls indicted in the MM section. The percentages of the cells positive for viral protein Env was determined by flow cytometric analysis. HMC3 cells were transfected with the indicated siRNAs pool, treated or not with IFN $\alpha 2(200 \mathrm{U} / \mathrm{mL})$ for 24 hours and infected with VSV for 18 hours (C) or MeV-GFP for 24 hours (D), at the MOls indicted in the MM section. The percentages of the cells positive for viral protein G or GFP were determined by flow cytometric analysis. Data are expressed relatively to the siRNA NT control of each experiment. Data are means \pm SD of three or four independent experiments, ${ }^{*} p<0.05,{ }^{* *} p<0.01$, ${ }^{* * *} p<0.001$, paired $t$-tests. 
12 and $\mathrm{C} 19$ orf66 are low in HMC3 cells, even when stimulated by IFN $\alpha 2$, and therefore are poorly, if at all, downregulated by specific siRNAs.

We validated the role of 5 hits as genes contributing to an optimal ZIKV replication in stimulated HMC3 cells using RT-qPCR and flow cytometry analysis: LY6E, USP18, ISG15, APOL3 and NAPA. The identification of LY6E as a gene enhancing ZIKV replication was expected, since it was previously shown to promote the internalization of flaviviruses in U2OS human osteosarcoma cells. ${ }^{25}$ Since ISG15 and USP18 negatively regulate IFN signaling pathway, ${ }^{61,62}$ they are expected to act as broad pro-viral ISGs. NAPA interacts with SNARE protein complexes to trigger their disassembly. ${ }^{63}$ SNARE proteins belong to a superfamily of membrane fusion proteins that localize at the plasma membrane, the Golgi apparatus and on different endocytic vesicles. They regulate the traffic of these vesicles between the plasma membrane and the Golgi. ${ }^{64}$ Several viruses, including influenza A virus and VSV, hijack SNARE proteins to enter host cells. ${ }^{65}$ SNARE complexes may thus contribute to NAPA pro-viral activities. We validated the anti-viral functions of 4 screen hits in stimulated HMC3 cells infected with ZIKV: IRF9, IFITM3, MTA2 and GPD2. Identification of IRF9, which plays a key role in ISG expression, ${ }^{26}$ and IFITM3, which restricts early stages of ZIKV infection, ${ }^{23,24}$ validates further our screening strategy. GPD2 is a mitochondrial protein involves in the metabolism of glycerol. No link between GPD2 and viral infections has been established yet. However, it regulates inflammatory response in macrophages. ${ }^{66}$ Further experiments will be required to confirm that NAPA and GPD2 have the ability to modulate ZIKV replication in stimulated human cells.

Experiments performed on cells infected with HCV or SARS-CoV-2 contributed to delineate the spectrum of action of a selection of the screen hits. Our data illustrate once again that some ISGs have virus-specific antiviral activities. ${ }^{67}$ For instance, we found that ZIKV, but not the related $\mathrm{HCV}$, was sensitive to IFITM3 expression, confirming ( $\mathrm{HCV}$ ) and extending (ZIKV) recently reported data. ${ }^{24,68}$ Our data also confirm that some ISGs exert opposite effect on different viruses. For instance, as described previously, LYE6 promotes the replication of $\mathrm{ZIKV}^{25}$ but restricts that of SARS-CoV-2. ${ }^{36}$ Viruses have developed numerous innovative strategies to evade ISG-mediated restriction. ${ }^{69,70}$ Hijacking individual ISG for promoting their replication is one of them. This hypothesis may explain why, to our surprise, our screen recovered more pro-viral genes that antiviral ones.

Our results identified APOL3 and APOL1 as ISGs required for optimal ZIKV replication in HMC3 cells. The proviral activity of APOL1 was less dependent on IFN that the one of APOL3, which suggest that both proteins act via different mechanisms.
Reduced expression of APOL1 and APOL3 also restricted the replication of WNV and DENV in stimulated $\mathrm{HMC} 3$ cells. In line with these findings, over-expression of APOL1 was previously reported to increase YFV replication in Huh-7 cells. ${ }^{20}$ VSV replication was highly reduced in the absence of one of these 2 genes. APOL 1 has been reported to act as an antiviral ISG in the context of infection with alphaviruses (Sindbis virus and Venezuelan equine encephalitis virus) and human parainfluenza virus. ${ }^{20,71}$ Its over-expression also inhibits HIV-1 infection in monocytes. ${ }^{72}$ Thus, APOL1 and APOL3 seem to behave like pro- or anti-viral ISG depending on the virus, or have no obvious role $(\mathrm{HCV})$. In line with our data on flaviviruses, a recent report found that overexpression of APOL1 promoted infection with ZIKV and DENV2 , confirming a proviral role for this factor. ${ }^{73}$ However in this study, an increase of ZIKV, DENV-2 and HCV replication was also reported in Huh-7.5 cells expressing siRNAs targeting APOL1 and APOL3 in the absence of IFN treatment ${ }^{73}$ yielding conflicting data that will deserve further investigation.

We formulated the hypothesis that APOL1 and APOL3 pro-viral activities could be linked to their ability to bind to anionic phospholipids, including several phosphoinositides, in particular $\mathrm{PI}(4) \mathrm{P} .{ }^{42}$ Both APOL1 and APOL3 were detected in PI(4)Pcontaining liposomes. ${ }^{42}$ Moreover, reduced expression of APOL3 resulted in reduction of $\mathrm{PI}(4) \mathrm{P}$ levels in podocytes. ${ }^{42} \mathrm{PI}(4) \mathrm{P}$ plays a pivotal role in the Golgi secretory functions by facilitating recruitment of proteins that promote vesicular transport. ${ }^{43}$ Our immunofluorescence data revealed that GFPtagged versions of APOL1 and APOL3 localize mainly in the Golgi, where $\mathrm{PI}(4) \mathrm{P}$ localizes. ${ }^{43}$ Numerous RNA viruses, including various Picornaviridae, HCV, coronaviruses and parainfluenza type 3 , rely on $\mathrm{PI}(4) \mathrm{P}$ to build membranous replication platform, where viral replication and assembly take place. ${ }^{74}$ Flaviviruses are no exception. ${ }^{75}$ Experiments conducted with a PI4KB kinase inhibitor excluded the possibility that APOL1 and APOL3 pro-viral effects depend on $\mathrm{PI}(4) \mathrm{P}$ and its synthetizing protein, $\mathrm{PI} 4 \mathrm{~KB}$. In line with these results, $\mathrm{PI}(4) \mathrm{P}$ are not important for the replication of WNV and the related Usutu virus. ${ }^{49}$ Other avenues should be thus explored to understand how APOL1 and APOL3 modulate the replication of several RNA viruses. Since APOL1 and APOL3 impact the replication of unrelated viruses, they may be negative regulators of IFN signalling pathway, by, for instance, contributing to the proper routing of members of the JAK/STAT pathway.

Our data revealed that MTA2 possesses potent antiviral function in the context of ZIKV, WNV and YFV in stimulated cells, whereas its exhibited a modest proviral role for $\mathrm{HCV}, \mathrm{VSV}$ and $\mathrm{MeV}$. Reducing MTA2 expression in the presence of IFN $\alpha 2$ enhanced flaviviral replication to a level 
comparable to the inhibition of IFNAR1. Despite being part of our gene list, MTA2 is not induced by IFN in HMC3 Huh-7 cells but its antiviral activity was dependent on IFN in these cells. MTA2 may thus interact with an ISG to act on viral replication. MTA2 is a component of the NuRD complex, an unusual complex which exhibits ATP-dependent chromatin remodeling activity in addition to histone deacetylase activity. ${ }^{28}$

MTA2 related activities have not, so far, been linked to innate immunity in virus-infected cells. However, a link between the NuRD complex and STAT1-mediated IFN response was established in the context of infection with the protozoan parasite Toxoplasma gondii. ${ }^{76}$ A Toxoplasma protein, named TgIST, translocates to the host cell nucleus where it recruits the complex NuRD to STAT1dependent promoters, resulting in altered chromatin and blocked STAT1-mediated transcription. ${ }^{76}$ Moreover, HDAC1, which is also a member of the NuRD complex, associates with both STAT1 and STAT2 in human cells. ${ }^{77}$ Furthermore, specific reduction of HDAC1 expression inhibits IFN $\beta$ induced transcription whereas HDAC1 overexpression enhances IFN $\beta$-induced transcription. ${ }^{77}$ Finally, HDAC inhibitors block the formation of ISGF3 and this was associated with impairment of STAT2 nuclear accumulation in mouse L929 cells. ${ }^{78}$ These findings indicate a fundamental role for deacetylase activity and HDAC1 in transcriptional control in response to IFN. One could thus envisage that MTA2, within the NuRD complex, also interacts with STAT1 in cells stimulated with IFN and favors its action locally. This interaction could restrict flavivirus infection, possibly via enhancing the expression of a subset of flavivirusspecific ISGs.

Our work identified previously unrecognized genes that modulate the replication of RNA viruses in an IFN-dependent way. Future studies combining transcriptomic analysis of IFN-treated cells and high throughput loss-of-function screens will help define the interferome of cell types relevant for viral infection. Such studies are primordial to continue investigating the complexity the IFN-mediated antiviral program.

\section{Materials and methods}

\section{Cells}

Human microglial cells (HMC3) were purchased from the American Type Culture Collection (ATCC, CRL-3304). They were maintained in Dulbecco's modified Eagle's medium (DMEM) containing GlutaMAX I and sodium pyruvate (Gibco), supplemented with $10 \%$ fetal bovine serum (FBS) and 1\% penicillin-streptomycin (P/S) (final concentration of 100 units/mL and $100 \mu \mathrm{g} /$ $\mathrm{mL}$, respectively) (Sigma) and non-essential amino acids (GibcoTM NEAA 100X MEM, Life Technologies). Podocytes were described previously. ${ }^{79}$ They were grown at $33^{\circ} \mathrm{C}$ in Roswell Park Memorial Institute medium (RPMI) containing GlutaMAX I (Gibco) and supplemented with 10\% FBS and P/S. Before any experiments, cells were differentiated during 7 days at $37^{\circ} \mathrm{C}$. Human hepatocellular carcinoma Huh-7 cells, ${ }^{80}$ which were kindly given by Cinzia Traboni (IRBM, Pomezia, Italy), were maintained in DMEM supplemented with $10 \%$ FBS and $1 \% \mathrm{P} / \mathrm{S}$. Huh-7.5 cells (Apath, LLC), a subclone of Huh-7 cells ${ }^{80}$ were cultured in DMEM supplemented with non-essential amino acids, $1 \mathrm{mM}$ sodium pyruvate, $10 \% \mathrm{FBS}$ and $\mathrm{P} / \mathrm{S}$. Vero NK cells, which are African green monkey kidney epithelial cells, were purchased from ATCC and used for viral titration assays. They were maintained in DMEM containing GlutaMAX I and sodium pyruvate (Gibco), supplemented with $10 \% \mathrm{FBS}$ and $\mathrm{P} / \mathrm{S}$. Aedes albopictus C6-36 cells were maintained in Leibovitz's L-15 medium containing 10\% FBS, 1\% $\mathrm{P} / \mathrm{S}, 1 \%$ Non-Essential Amino Acids Solution (Gibco) and 2\% Tryptose Phosphate Browth (Gibco). Human lung epithelial A549 cells were modified to stably express hACE2 using the pLenti6-hACE2 lentiviral transduction, as described previously. ${ }^{81}$ Cell cultures were verified to be mycoplasma free with the MycoAlertTM Mycoplasma Detection Kit (Lonza).

\section{Virus stocks, titration and infection}

The Zika strain PF13 (kindly provided by V. M. Cao-Lormeau and D. Musso, Institut Louis Malardé, Tahiti Island, French Polynesia) was isolated from a viremic patient in French Polynesia in 2013. Stocks were produced on C6-36 cells. The Dengue 2 virus (DENV-2) strain Malaysia SB8553 was obtained from the Centro de Ingeniería Genética y Biotecnología (CIGB), Cuba. The YFV Asibi strain and the WNV Israeli strain IS-98-STI were provided by the Biological resource Center of the Institut Pasteur. Stocks of DENV-2, YFV and WNV were produced on Vero NK cells. Viruses were concentrated by polyethylene glycol 6000 precipitation and purified by centrifugation in a discontinued gradient of sucrose. Flaviviruses were titrated on Vero NK cells by plaque assay as previously described ${ }^{82}$ and titers were expressed in plaque-forming units (PFU)/ml. The Measles Schwarz strain expressing GFP (MeV-GFP) was described previously. ${ }^{41}$ VSV Indiana and the CVB3 Nancy strain were kindly provided by N. Escriou (Institut Pasteur) and M. Bessaud, respectively (Institut Pasteur). Modified Vaccinia Ankara virus (MVA) expressing eGFP (MVA-GFP) was kindly provided by the ANRS via O. Schwartz (Institut Pasteur). It was manufactured by Transgene (Illkirch-Graffenstaden, France). The fluorescent marker, eGFP, is expressed under the control of the early promotor $\mathrm{p} 11 \mathrm{~K} 7.5$ and viral preparations were purified by tangential flow filtration. HMC3 cells were infected at the following MOIs: a MOI of 10 with DENV-2, 0.5 with WNV, 
0.005 with VSV, 1 with MeV-GFP and 0.05 with MVA-GFP. IFN-treated HMC3 cells were infected at a MOI of 20 with DENV-2, 5 with WNV, 0.01 with VSV, 2 with MeV-GFP and 0.25 with MVA-GFP. Huh-7 were infected at a $\mathrm{MOI}$ of 1 with YFV and 0.25 with WNV. IFN-treated Huh-7 cells were infected at a MOI of 10 with YFV and WNV. Highly cell culture-adapted HCV Jad strain was obtained following transfection of Huh-7.5 cells with in vitro transcribed genome-length RNA as described previously. ${ }^{83-85}$ Large volumes of $\mathrm{HCV}$ stocks were prepared following infection at a $\mathrm{MOI}$ of $0.0150 \%$ tissue culture infectious doses 50 (TCID50) per cell with supernatants collected post-RNA transfection. $^{86} \mathrm{HCV}$ infectious titers were determined by TCID50 assays in Huh-7.5 cells as described previously, ${ }^{83}$ with a limit of detection of $80 \mathrm{TCID} 50 / \mathrm{mL}$. IFN-treated Huh-7.5 cells were infected at $\mathrm{MOI}$ of 3 TCID50/cell with HCV. The SARS-CoV-2 strain BetaCoV/France/IDF0372/2020 (historical) was supplied by the French National Reference Centre for Respiratory Viruses hosted by Institut Pasteur (Paris, France) and headed by Pr. S. van der Werf. The human samples from which the strain was isolated were provided by Dr. X. Lescure and Pr. Y. Yazdanpanah from the Bichat Hospital, Paris, France and Dr. Vincent Foissaud, HIA Percy, Clamart, France, respectively. A549-ACE2 cells were infected with SARS-CoV-2 at a MOI of 2.

\section{High throughput screen}

Five hundreds HMC3 cells were seeded in 384well microplates in the morning of day 1 using a MultiDrop combi liquid dispenser (Thermo Fisher Scientific), in $40 \mu \mathrm{L}$ of cell culture media. Cells were allowed to adhere for 4 hours before transfection with individual siRNAs (10 nM) diluted in a mix of OptiMEM (Life Technologies) and $0.05 \mu \mathrm{L}$ of Interferin reagent (Polyplus Transfection). siRNAs were transfected using an Evo 150 with MCA384 (Tecan). The library contained 1158 siRNA targeting 386 genes. siRNA targeting KIF11 was used to assess the transfection efficiency. On day 2, cells were treated with $1000 \mathrm{U} / \mathrm{ml}$ of IFN $\alpha 2 a$. Interferon was diluted into cell culture media and $10 \mu \mathrm{L}$ of the mix was robotically transferred to each well (except non-treated controls). 24 hours after IFN treatment, cell media was removed from siRNAtransfected plates and $40 \mu \mathrm{L}$ of the ZIKV PF13 strain, diluted to a final concentration of 7,500 particles/well, was added to the plates with the MCA384 head (Tecan). ZIKV titer was 6.5.10 PFU/ml. Cells were then incubated 24 hours prior to fixation. Cells were fixed with $4 \%$ of formaldehyde (Sigma-Aldrich) for $20 \mathrm{~min}$, plates were then washed once with PBS and quenched with $\mathrm{NH} 4 \mathrm{Cl}(50 \mathrm{mM})$ solution. Cells were then blocked with 1\% BSA solution and permeabilized with $0.5 \%$ Triton $X-100$. Cells were next incubated for 60 min with mouse primary antibody anti-4G2 (1:500) which reacts with flavivirus $E$ proteins. Cells were then washed twice in PBS solution and incubated with Alexa Fluor 488-coupled secondary antibodies (ThermoFisher Scientific). Nuclei were stained with $0.2 \mu \mathrm{g} / \mathrm{ml}$ Hoechst (Sigma). Images were acquired with an INCell2200 automated wide-field system (GE Healthcare,) using a Nikon 10X/0.45, Plan Apo, CFI/60. Three fields per well were analyzed using the INCell Analyzer 3.7 Workstation software. Two independent screens were performed. The mean cell count and the percentages of infected cells were extracted from quantification.

For quality control purposes, the number of cells in each condition of the 2 replicates were analysed. We observed an expected distribution of the number of cells in 3 fields with a median close to 1000 cells per well for the two replicates (Figure $\mathrm{S1}(\mathrm{B})$ ). The number of cells per condition was slightly higher in the first replicate than in the second one. However, the $R^{2}$ coefficient of determination of the linear regression was close to 0.7 (Figure $\mathrm{S} 1(\mathrm{C})$ ), indicating that the reproducibility of the experiment was correct. As expected, ${ }^{22}$ siRNAs against KIF11 were lethal, validating the transfection protocol (Figure S1(B, C)). The number of cells expressing the viral protein $E$ distributed as predicted, with a median close to $15 \%$ for the 2 screens (Figure S1(D)). As expected from pilot experiments (Figure $S 1(A)$ ), siRNAs targeting IFNAR-1 and -2 rescued ZIKV replication in IFN-treated cells (Figure $S 1(D, E)$ ). The reproducibility of the infection status of the cells between the 2 screens, with a $R^{2}$ greater than 0.8 , was satisfactory (Figure S1(E)).

\section{Data analysis and hit calling}

In the first analysis, data were processed using a software developed internally at the Biophenics platform. For hit identification, the robust Z-score method was used under the assumption that most siRNAs are inactive against ZIKV and can serve as controls. ${ }^{87,88}$ Raw values were logtransformed for cell count only to make the data more symmetric and close to normal distribution. In order to correct for plate positional effects, median polishing ${ }^{88}$ was applied to each analyzed feature. It iteratively subtracts row, column and well median, computed from all plates within one screen. Hits for each compound were identified as follows: sample median and median absolute deviation (MAD) were calculated from the population of screening data points (named as sample) and used to compute Robust Z-scores (RZscores) according to a formula, in which the reference population corresponds to the siRNA-treated wells, and MAD is defined as the median of the absolute deviation from the median of the corresponding wells: 


$$
r Z-\text { Score }=\frac{x-\operatorname{med}\left(\text { pop } r \hat{A}^{\prime} f\right)}{1.4826 x \operatorname{med}\left(\left|p o p r \hat{A}^{\prime} f-\operatorname{med}\left(p o p r \hat{A}^{\prime} f\right)\right|\right)}
$$

A gene was identified as a 'hit', if the RZ-score was $<-2$ or $>2$ pointing in the same direction for 2 siRNAs targeting the same gene in both screens. Final values in the hit table correspond to the RZscore of the second strongest siRNA. In the second analysis, data were process using an homemade script and CellProfiler. ${ }^{89}$ Nucleus and viral assembly sites detected by the $E$ signal were counted. As in the first analysis, rZ-Score and percentages of infected cells were quantified. Considering that each gene was targeted by three individual siRNA, genes were clusterized as hits, if at least two over three of their robust $Z$ score absolute value were superior to 2. Genes were defined as hits when they were identified in at least one of the analysis.

\section{Antibodies, plasmids and reagents}

The following primary antibodies were used in the study: anti-E MAb 4G2 hybridoma cells, anti-NS5ZIKV, ${ }^{90}$ anti-VSV-G (IE9F9, Kerafast), anti-CVB3 VP1 (M7064, Agilent), anti-SARS-CoV-2 S protein mAb10 $(1 \mu \mathrm{g} / \mathrm{ml}$, a kind gift from $\mathrm{H}$. Mouquet, Institut Pasteur, Paris, France), APOL1 (HPA018885, Sigma), MTA2 (8106, abcam), GM130 (12480, cell signaling), $\mathrm{PI}(4) \mathrm{P}$ (Z-P004), PI(4)KB (06-578, Milipore) and anti-actin (A5316, Sigma). Secondary antibodies were as followed: anti-mouse Alexa 488 (A11001, Life Technologies), anti-mouse Alexa 680 (A21058, Life Technologies) and anti-rabbit DyLight 800 (SA5-35571, TermoScientific). The PI4KB inhibitor (1881233-39-1, MedChemExpress) and IFNa2a (Sigma-Aldrich, SRE0013) were used at the indicated concentration. GFP-APOL3 et APOL3-GFP were subcloned into pcDNA.3.1 from templates previously described. ${ }^{42}$

siRNA transfection

HMC3 cells were transfected using INTERFERin transfection reagent (Polyplus Transfection). Huh-7 cells, Huh-7.5 cells and podocytes were transfected with siRNAs at $10 \mathrm{nM}$ final concentration using Lipofectamine RNAiMax (Life Technologies). All siRNAs were obtained from Dharmacon (siGENOME-SMARTpool).

\section{RNA extraction and RT-qPCR assays}

Total RNAs were extracted from cell lysates using the NucleoSpin RNA II Kit (Macherey-Nagel) following the manufacturer's protocol and were eluted in nuclease-free water. First-strand complementary DNA synthesis was performed with the RevertAid $H$ Minus M-MuLV Reverse Transcriptase (Thermo Fisher Scientific). Quantitative real-time PCR was performed on a real-time PCR system (QuantStudio 6 Flex, Applied Biosystems) with SYBR Green PCR
Master Mix (Life Technologies). Data were analyzed with the $\triangle \triangle C T$ method, with all samples normalized to GAPDH. All experiments were performed in technical triplicate. Viral genome equivalents concentrations (GE/ml) were determined by extrapolation from a standard curve generated from serial dilutions of the plasmid encoding the full-length genome of the Zika strain MR766 ${ }^{91}$ or plasmids encoding a fragment of the RNA-dependent RNA polymerase (RdRp)-IP4 of SARS-CoV-2. HCV RNA was quantified by onestep reverse transcription-quantitative PCR using 50 ng of total intracellular RNA and TaqMan ${ }^{\circledR}$ Fast Virus 1-Step Master Mix (Applied Biosystems) with primers and probe targeting the $\mathrm{HCV} 5^{\prime}$ nontranslated region as described previously. ${ }^{86}$ Viral RNA levels were normalized with respect to 18S RNA levels quantified in parallel using TaqMan ribosomal RNA control reagents (Applied Biosystems). The products were analysed on a 7500 Fast RealTime PCR system (Applied Biosystems). Serial dilutions of a genome-length in vitro transcribed HCV RNA served to establish standard curves and calculate $\mathrm{HCV}$ GE/ $\mu \mathrm{g}$ total RNA concentrations. Primers and probe used for RT-qPCR analysis are given in Table S2.

\section{Western blot analysis}

Cells were collected in RIPA buffer (Sigma) containing protease inhibitors (Roche Applied Science). Cell lysates were normalized for protein content with Pierce $660 \mathrm{~nm}$ Protein Assay (Thermo Scientific), boiled in NuPAGE LDS sample buffer (Thermo Fisher Scientific) in nonreducing conditions. Samples were separated by SDS-PAGE (NuPAGE 4-12\% Bis-Tris Gel, Life Technologies) with MOPS running buffer. Separated proteins were transferred to a nitrocellulose membrane (Bio-Rad). After blocking with PBS-Tween-20 0.1\% (PBST) containing 5\% milk for $1 \mathrm{~h}$ at RT, the membrane was incubated overnight at $4{ }^{\circ} \mathrm{C}$ with primary antibodies diluted in blocking buffer. Finally, the membranes were incubated for $1 \mathrm{~h}$ at RT with secondary antibodies diluted in blocking buffer, washed, and scanned using an Odyssey CLx infrared imaging system (LI-COR Bioscience).

\section{Flow cytometry}

Infected cells were fixed with cytofix/cytoperm kit (BD Pharmingen) and stained using the indicated primary and secondary antibodies. Non-infected, antibody-stained samples served as controls for signal background. Data were acquired using Attune NxT Acoustic Focusing Cytometer (Life Technologies) and analyzed using FlowJo software. 


\section{Immunofluorescence assay}

Cells were fixed with PFA 4\% (Sigma) during 20 min. Cells were permeabilized with PBS Triton X-100 (0.5\%) for $15 \mathrm{~min}$ at RT. After washing with PBS, they were incubated for $30 \mathrm{~min}$ with PBS $+0.05 \%$ Tween $20+5 \%$ BSA. The slides were then incubated overnight at $4{ }^{\circ} \mathrm{C}$ with primary antibodies diluted in PBS. After washing with PBS, they were incubated for $1 \mathrm{~h}$ with secondary antibodies and washed with PBS. Nuclei were stained using PBS/NucBlue (Life Technologies, R37606). The mounting medium used is the Prolong gold (Life Technologies, P36930). All preparations were observed with a confocal microscope (ZEISS LSM 700 inverted) and images were acquired with the ZEN software.

\section{Statistical analysis}

Data are presented as means \pm SD and were analyzed using GraphPad Prism 7. Statistical analysis of percentage values or fold enrichment values were performed on logit or log-transformed values, respectively. Statistical analysis was performed with two tailed paired $t$-test or by oneor two-way analysis of variance (ANOVA) with Dunnet's multiple comparisons test. Each experiment was performed at least twice, unless otherwise stated. Statistically significant differences are indicated as follows: ${ }^{*}: p<0.05,{ }^{* *}$ : $p<0.01$ and ${ }^{* * *}: p<0.001 ;$ ns, not significant.

\section{CRediT authorship contribution statement}

Sarah Lesage: Investigation, Conceptualization, Methodology, Validation, Formal analysis, Writing - review \& editing, Visualization. Maxime Chazal: Investigation, Conceptualization, Methodology, Validation, Formal analysis, Writing - review \& editing, Visualization. Guillaume Beauclair: Conceptualization, Software, Writing - review \& editing, Visualization. Damien Batalie: Investigation, Conceptualization. Silvia Cerboni: Conceptualization, Methodology, Resources. Elodie Couderc: Investigation, Writing - review \& editing. Aurianne Lescure: Investigation, Conceptualization, Methodology, Resources, Writing - review \& editing. Elaine Del Nery: Conceptualization, Methodology, Resources, Writing - review \& editing. Frédéric Tangy: Funding acquisition. Annette Martin: Conceptualization, Methodology, Validation, Formal analysis, Writing - review \& editing, Visualization, Supervision, Funding acquisition. Nicolas Manel: Conceptualization, Methodology, Resources, Writing - review \& editing, Funding acquisition. Nolwenn Jouvenet: Conceptualization, Methodology, Validation, Writing - original draft, Writing - review \& editing, Visualization, Supervision, Funding acquisition.

\section{Acknowledgements}

We thank Dr. M.A. Saleem (University of Bristol, UK) for generously providing the podocytes (via E. Pays, Université Libre de Bruxelles, Belgium); C. M. Rice (Rockefeller University, New York, USA) for Huh-7.5 cells; Cinzia Traboni (IRBM, Pomezia, Italy) for Huh-7 cells; M. Bessaud (Institut Pasteur) for the CVB3 Nancy strain; N. Escriou (Institut Pasteur) for the VSV Indiana strain and anti-VSVG antibodies; V. M. Cao-Lormeau and D. Musso (Institut Louis Malardé, Tahiti Island, French Polynesia) for the ZIKV-PF13 strain; L. Hermida and G. Enrique Guillen Nieto from the Centro de Ingeniería Genética y Biotecnología (CIGB), Cuba, for the DENV-2 strain Malaysia SB8553; T. Wakita (NIID, Tokyo, Japan) for pJFH1 HCV cDNA; R. Bartenschlager (University of Heidelberg, Germany) for pJFH1-2El3-adapt cDNA; the French National Reference Centre for Respiratory Viruses hosted by Institut Pasteur (France) and headed by $S$. van der Werf for providing the historical SARS-CoV-2 viral strains; A. Merits (University of Tartu, Estonia) for anti-ZIKV NS5 antibodies; P. Desprès (Université de la Réunion, PIMIT) for 4G2 hybridoma cells; $H$. Mouquet (Institut Pasteur) for anti-SARS-CoV-2 S antibodies; M. Evans (Icahn School of Medicine at Mount Sinai, New York, USA) for the plasmid encoding the full-length Zika MR766 genome; F. Porrot and $O$. Schwartz (Institut Pasteur) for sharing MVA-GFP, C. Combredet (Institut Pasteur) for producing MeV-GFP; P. Benaroch (Institut Curie, France) for advice concerning the siRNA screening work, as well as E. Pays and S. Uzureau (Université Libre de Bruxelles, Belgium) for APOL1 and APOL3 plasmids and for stimulating APOLfocused discussions. We are grateful to the members of our laboratories for helpful discussions and technical advice. Finally, we thank Emeline Perthame (Bioinformatics and Biostatistics HUB, Institut Pasteur) for her help in statistical analysis.

This work was funded by the CNRS, INSERM, Institut Pasteur, Institut Curie, 'Urgence COVID19' fundraising campaign of Institut Pasteur, LABEX VRI (ANR-10-LABX-77), LABEX DCBIOL (ANR-10-IDEX-0001-02 PSL* and ANR-11LABX0043), the Région Ile-de-France (DIM1HEALTH 2019), EMBO Young Investigator programm bringing fund and the Agence Nationale de la Recherche sur le sida et les hépatites virales (ANRS-CSS12-2019-2). The BioPhenics laboratory is supported by Institut Curie, IBiSA (PICT-IBiSA) and part of ChemBioFRance and France-Biolmaging infrastructure supported by the French National Research Agency (ANR-10-INSB04, ûlnvestments for the futureý). SL was the recipient of a Université de Paris PhD fellowship. The funders had no role in study design, data collection and analysis, decision to publish, or preparation of the manuscript. 


\section{Declaration of interests}

The authors declare no competing interests.

\section{Appendix A. Supplementary material}

Supplementary data to this article can be found online at https://doi.org/10.1016/j.jmb.2021. 167277.

Received 16 August 2021; Accepted 22 September 2021; Available online $x x x x$

Keywords:

Zika virus; antiviral response; interferon-stimulated genes; APOL3; MTA2

$\dagger$ These authors contributed equally.

\section{References}

1. Woolhouse, M., Scott, F., Hudson, Z., Howey, R., ChaseTopping, M., (2012). Human viruses: discovery and emergence. Philos. Trans. R. Soc. Lond. B Biol. Sci., 367, 2864-2871. https://doi.org/10.1098/rstb.2011.0354.

2. Streicher, F., Jouvenet, N., (2019). Stimulation of Innate Immunity by Host and Viral RNAs. Trends Immunol., 40, 1134-1148. https://doi.org/10.1016/j.it.2019.10.009.

3. Mesev, E.V., LeDesma, R.A., Ploss, A., (2019). Decoding type I and III interferon signalling during viral infection. Nature Microbiol., 4, 914-924. https://doi.org/10.1038/ s41564-019-0421-x.

4. Schoggins, J.W., (2018). Recent advances in antiviral interferon-stimulated gene biology. F1000Res., 7 https:// doi.org/10.12688/f1000research.12450.1.

5. Rusinova, I., Forster, S., Yu, S., Kannan, A., Masse, M., Cumming, H., et al., (2013). Interferome v2.0: an updated database of annotated interferon-regulated genes. Nucleic Acids Res., 41, D1040-D1046. https://doi.org/10.1093/nar/ gks1215.

6. Touzot, M., Grandclaudon, M., Cappuccio, A., Satoh, T., Martinez-Cingolani, C., Servant, N., et al., (2014). Combinatorial flexibility of cytokine function during human T helper cell differentiation. Nature Commun., 5, 3987. https://doi.org/10.1038/ncomms4987.

7. Mostafavi, S., Yoshida, H., Moodley, D., LeBoité, H., Rothamel, K., Raj, T., et al., (2016). Parsing the interferon transcriptional network and its disease associations. Cell, 164, 564-578. https://doi.org/10.1016/ j.cell.2015.12.032.

8. Schneider, W.M., Chevillotte, M.D., Rice, C.M., (2014). Interferon-Stimulated Genes: A Complex Web of Host Defenses. Annu. Rev. Immunol., 32, 513-545. https://doi. org/10.1146/annurev-immunol-032713-120231.

9. Pierson, T.C., Diamond, M.S., (2020). The continued threat of emerging flaviviruses. Nature Microbiol.,. https://doi.org/ 10.1038/s41564-020-0714-0.
10. Ashraf, U., Ye, J., Ruan, X., Wan, S., Zhu, B., Cao, S., (2015). Usutu virus: an emerging flavivirus in Europe. Viruses, 7, 219-238. https://doi.org/10.3390/ v7010219.

11. Pierson, T.C., Diamond, M.S., (2018). The emergence of Zika virus and its new clinical syndromes. Nature, 560, 573-581. https://doi.org/10.1038/s41586-018-0446-y.

12. Matusali, G., Houzet, L., Satie, A.-P., Mahé, D., Aubry, F., Couderc, T., et al., (2018). Zika virus infects human testicular tissue and germ cells. J. Clin. Invest., 128, 4697-4710. https://doi.org/10.1172/JCl121735.

13. Rossi, S.L., Tesh, R.B., Azar, S.R., Muruato, A.E., Hanley, K.A., Auguste, A.J., et al., (2016). Characterization of a Novel Murine Model to Study Zika Virus. Am. J. Trop. Med. Hyg., 94, 1362-1369. https://doi.org/10.4269/ajtmh.160111.

14. Lazear, H.M., Govero, J., Smith, A.M., Platt, D.J., Fernandez, E., Miner, J.J., et al., (2016). A Mouse Model of Zika Virus Pathogenesis. Cell Host Microbe, 19, 720730. https://doi.org/10.1016/j.chom.2016.03.010.

15. Tripathi, S., Balasubramaniam, V.R., Brown, J.A., Mena, I., Grant, A., Bardina, S.V., et al., (2017). A novel Zika virus mouse model reveals strain specific differences in virus pathogenesis and host inflammatory immune responses. PLoS Pathog., 13, https://doi.org/10.1371/journal. ppat.1006258 e1006258.

16. Xia, H., Luo, H., Shan, C., Muruato, A.E., Nunes, B.T.D., Medeiros, D.B.A., et al., (2018). An evolutionary NS1 mutation enhances Zika virus evasion of host interferon induction. Nature Commun., 9, 414. https://doi.org/ 10.1038/s41467-017-02816-2.

17. Meertens, L., Labeau, A., Dejarnac, O., Cipriani, S., Sinigaglia, L., Bonnet-Madin, L., et al., (2017). Axl Mediates ZIKA Virus Entry in Human Glial Cells and Modulates Innate Immune Responses. Cell Rep., 18, 324333. https://doi.org/10.1016/j.celrep.2016.12.045.

18. Xu, P., Shan, C., Dunn, T.J., Xie, X., Xia, H., Gao, J., et al., (2020). Role of microglia in the dissemination of Zika virus from mother to fetal brain. PLoS Negl. Trop. Dis., 14 https:// doi.org/10.1371/journal.pntd.0008413.

19. Wang, J., Liu, J., Zhou, R., Ding, X., Zhang, Q., Zhang, C., et al., (2018). Zika virus infected primary microglia impairs NPCs proliferation and differentiation. Biochem. Biophys. Res. Commun., 497, 619-625. https://doi.org/10.1016/j. bbrc.2018.02.118.

20. Schoggins, J.W., Wilson, S.J., Panis, M., Murphy, M.Y., Jones, C.T., Bieniasz, P., et al., (2011). A diverse range of gene products are effectors of the type I interferon antiviral response. Nature, 472, 481-485. https://doi.org/ 10.1038/nature09907.

21. Liu, S.-Y., Sanchez, D.J., Aliyari, R., Lu, S., Cheng, G., (2012). Systematic identification of type I and type II interferon-induced antiviral factors. PNAS, 109, 42394244.

22. Groth-Pedersen, L., Aits, S., Corcelle-Termeau, E., Petersen, N.H.T., Nylandsted, J., Jäättelä, M., (2012). Identification of cytoskeleton-associated proteins essential for lysosomal stability and survival of human cancer cells. PLOS ONE, 7, https://doi.org/10.1371/journal. pone.0045381 e45381.

23. Savidis, G., Perreira, J.M., Portmann, J.M., Meraner, P., Guo, Z., Green, S., et al., (2016). The IFITMs Inhibit Zika Virus Replication. Cell Rep., 15, 2323-2330. https://doi. org/10.1016/j.celrep.2016.05.074. 
24. Monel, B., Compton, A.A., Bruel, T., Amraoui, S., BurlaudGaillard, J., Roy, N., et al., (2017). Zika virus induces massive cytoplasmic vacuolization and paraptosis-like death in infected cells. EMBO J., 36, 1653-1668. https:// doi.org/10.15252/embj.201695597.

25. Hackett, B.A., Cherry, S., (2018). Flavivirus internalization is regulated by a size-dependent endocytic pathway. Proc. Natl. Acad. Sci. U. S. A., 115, 4246-4251. https://doi.org/ 10.1073/pnas.1720032115.

26. Paul, A., Tang, T.H., Ng, S.K., (2018). Interferon Regulatory Factor 9 Structure and Regulation. Front. Immunol., 9 https://doi.org/10.3389/fimmu.2018.01831.

27. Smith, S., Weston, S., Kellam, P., Marsh, M., (2014). IFITM proteins-cellular inhibitors of viral entry. Curr Opin Virol., 4, 71-77. https://doi.org/10.1016/j.coviro.2013.11.004.

28. Lai, A.Y., Wade, P.A., (2011). NuRD: A multi-faceted chromatin remodeling complex in regulating cancer biology. Nature Rev. Cancer, 11, 588-596. https://doi.org/ 10.1038/nrc3091.

29. Blight, K.J., McKeating, J.A., Rice, C.M., (2002). Highly permissive cell lines for subgenomic and genomic hepatitis C virus RNA replication. J. Virol., 76, 13001-13014.

30. Sumpter, R., Loo, Y.M., Foy, E., Li, K., Yoneyama, M., Fujita, T., et al., (2005). Regulating intracellular antiviral defense and permissiveness to hepatitis $C$ virus RNA replication through a cellular RNA helicase. RIG-I. J Virol., 79, 2689-2699. https://doi.org/10.1128/JVI.79.5.26892699.2005.

31. Mukherjee, A., Di Bisceglie, A.M., Ray, R.B., (2015). Hepatitis C virus-mediated enhancement of microRNA miR-373 impairs the JAK/STAT signaling pathway. J. Virol., 89, 3356-3365. https://doi.org/10.1128/JVI.0308514.

32. Li, Y., Ma, M.X., Qin, B., Lin, L.-T., Richardson, C.D., Feld, J., et al., (2019). The Ubiquitin-Specific Protease 18 Promotes Hepatitis C Virus Production by Increasing Viral Infectivity. Mediators Inflamm., 2019, https://doi.org/ 10.1155/2019/3124745 e3124745.

33. Randall, G., Chen, L., Panis, M., Fischer, A.K., Lindenbach, B.D., Sun, J., et al., (2006). Silencing of USP18 Potentiates the Antiviral Activity of Interferon Against Hepatitis C Virus Infection. Gastroenterology, 131, 1584-1591. https://doi.org/10.1053/ j.gastro.2006.08.043.

34. Arnaud, N., Dabo, S., Akazawa, D., Fukasawa, M., Shinkai-Ouchi, F., Hugon, J., et al., (2011). Hepatitis C virus reveals a novel early control in acute immune response. PLoS Pathog., 7, https://doi.org/10.1371/ journal.ppat.1002289 PPATHOGENS-D-11-00682 [pii] e1002289.

35. Chen, L., Sun, J., Meng, L., Heathcote, J., Edwards, A.M., McGilvray, I.D., (2010). ISG15, a ubiquitin-like interferonstimulated gene, promotes hepatitis $\mathrm{C}$ virus production in vitro: implications for chronic infection and response to treatment. J. Gen. Virol., 91, 382-388. https://doi.org/ 10.1099/vir.0.015388-0.

36. Pfaender, S., Mar, K.B., Michailidis, E., Kratzel, A., Boys, I. N., V'kovski P, et al., (2020). LY6E impairs coronavirus fusion and confers immune control of viral disease. Nature. Microbiology, 5, 1330-1339. https://doi.org/10.1038/ s41564-020-0769-y.

37. Vanhollebeke, B., Pays, E., (2006). The function of apolipoproteins L. Cell. Mol. Life Sci., 63, 1937-1944. https://doi.org/10.1007/s00018-006-6091-x.
38. Monajemi, H., Fontijn, R.D., Pannekoek, H., Horrevoets, A. J.G., (2002). The apolipoprotein L gene cluster has emerged recently in evolution and is expressed in human vascular tissue. Genomics, 79, 539-546. https://doi.org/ 10.1006/geno.2002.6729.

39. Malakhova, O.A., Kim, K.I., Luo, J.-K., Zou, W., Kumar, K. G.S., Fuchs, S.Y., et al., (2006). UBP43 is a novel regulator of interferon signaling independent of its ISG15 isopeptidase activity. EMBO J., 25, 2358-2367. https:// doi.org/10.1038/sj.emboj.7601149.

40. Alcendor, D.J., (2017). Zika Virus Infection of the Human Glomerular Cells: Implications for Viral Reservoirs and Renal Pathogenesis. J. Infect. Dis., 216, 162-171. https:// doi.org/10.1093/infdis/jix171.

41. Combredet, C., Labrousse, V., Mollet, L., Lorin, C., Delebecque, F., Hurtrel, B., et al., (2003). A Molecularly Cloned Schwarz Strain of Measles Virus Vaccine Induces Strong Immune Responses in Macaques and Transgenic Mice. J. Virol., 77, 11546-11554. https://doi.org/10.1128/ JVI.77.21.11546-11554.2003.

42. Uzureau, S., Lecordier, L., Uzureau, P., Hennig, D., Graversen, J.H., Homblé, F., et al., (2020). APOL1 CTerminal Variants May Trigger Kidney Disease through Interference with APOL3 Control of Actomyosin. Cell Rep., 30, 3821-3836.e13. https://doi.org/10.1016/j. celrep.2020.02.064.

43. Waugh, M.G., (2019). The Great Escape: how phosphatidylinositol 4-kinases and PI4P promote vesicle exit from the Golgi (and drive cancer). Biochem. J., 476, 2321-2346. https://doi.org/10.1042/BCJ20180622.

44. Delang, L., Paeshuyse, J., Neyts, J., (2012). The role of phosphatidylinositol 4-kinases and phosphatidylinositol 4-phosphate during viral replication. Biochem. Pharmacol., 84, 1400-1408. https://doi.org/ 10.1016/j.bcp.2012.07.034.

45. Strating, J.R., van Kuppeveld, F.J., (2017). Viral rewiring of cellular lipid metabolism to create membranous replication compartments. Curr. Opin. Cell Biol., 47, 24-33. https://doi. org/10.1016/j.ceb.2017.02.005.

46. Daboussi, L., Costaguta, G., Ghukasyan, R., Payne, G.S., (2017). Conserved role for Gga proteins in phosphatidylinositol 4-kinase localization to the transGolgi network. PNAS, 114, 3433-3438.

47. Rutaganira, F.U., Fowler, M.L., McPhail, J.A., Gelman, M. A., Nguyen, K., Xiong, A., et al., (2016). Design and Structural Characterization of Potent and Selective Inhibitors of Phosphatidylinositol 4 Kinase III $\beta$. J. Med. Chem., 59, 1830-1839. https://doi.org/10.1021/acs. jmedchem.5b01311.

48. Hsu, N.-Y., Ilnytska, O., Belov, G., Santiana, M., Chen, Y.H., Takvorian, P.M., et al., (2010). Viral reorganization of the secretory pathway generates distinct organelles for RNA replication. Cell, 141, 799-811. https://doi.org/ 10.1016/j.cell.2010.03.050.

49. Martín-Acebes, M.A., Blázquez, A.-B., Jiménez de Oya, N., Escribano-Romero, E., Saiz, J.-C., (2011). West Nile virus replication requires fatty acid synthesis but is independent on phosphatidylinositol-4-phosphate lipids. PLOS ONE, 6, https://doi.org/10.1371/journal.pone.0024970 e24970.

50. Sillibourne, J.E., Delaval, B., Redick, S., Sinha, M., Doxsey, S.J., (2007). Chromatin Remodeling Proteins Interact with Pericentrin to Regulate Centrosome Integrity. Mol. Biol. Cell, 18, 3667-3680. https://doi.org/ 10.1091/mbc.E06-07-0604. 
51. Zhao, Z., Tao, M., Han, W., Fan, Z., Imran, M., Cao, S., et al., (2021). Nuclear localization of Zika virus NS5 contributes to suppression of type I interferon production and response. J. Gen. Virol., 102 https://doi.org/10.1099/ jgv.0.001376.

52. Ji, W., Luo, G., (2020). Zika virus NS5 nuclear accumulation is protective of protein degradation and is required for viral RNA replication. Virology, 541, 124-135. https://doi.org/10.1016/j.virol.2019.10.010.

53. Jiang, D., Weidner, J.M., Qing, M., Pan, X.B., Guo, H., Xu, C., et al., (2010). Identification of five interferon-induced cellular proteins that inhibit west nile virus and dengue virus infections. J. Virol., 84, 8332-8341. https://doi.org/10.1128/ JVI.02199-09.

54. Itsui, Y., Sakamoto, N., Kurosaki, M., Kanazawa, N., Tanabe, Y., Koyama, T., et al., (2006). Expressional screening of interferon-stimulated genes for antiviral activity against hepatitis $\mathrm{C}$ virus replication. J Viral Hepat., 13, 690-700. https://doi.org/10.1111/j.13652893.2006.00732.x.

55. Van der Hoek, K.H., Eyre, N.S., Shue, B., Khantisitthiporn, O., Glab-Ampi, K., Carr, J.M., et al., (2017). Viperin is an important host restriction factor in control of Zika virus infection. Sci. Rep., 7, 4475. https://doi.org/10.1038/ s41598-017-04138-1.

56. Richardson, R.B., Ohlson, M.B., Eitson, J.L., Kumar, A., McDougal, M.B., Boys, I.N., et al., (2018). A CRISPR screen identifies IFI6 as an ER-resident interferon effector that blocks flavivirus replication. Nature Microbiol.,. https:// doi.org/10.1038/s41564-018-0244-1.

57. Li, L., Zhao, H., Liu, P., Li, C., Quanquin, N., Ji, X., et al., (2018). PARP12 suppresses Zika virus infection through PARP-dependent degradation of NS1 and NS3 viral proteins. Sci Signal., 11, eaas9332. https://doi.org/ 10.1126/scisignal.aas9332.

58. Wu, Y., Yang, X., Yao, Z., Dong, X., Zhang, D., Hu, Y., et al., (2020). C19orf66 interrupts Zika virus replication by inducing lysosomal degradation of viral NS3. PLoS Negl. Trop. Dis., 14, https://doi.org/10.1371/journal. pntd.0008083 e0008083.

59. Vanwalscappel, B., Gadea, G., Desprès, P., (2019). A Viperin Mutant Bearing the K358R Substitution Lost its Anti-ZIKA Virus Activity. Int. J. Mol. Sci., 20, E1574. https:// doi.org/10.3390/ijms20071574.

60. Lindqvist, R., Kurhade, C., Gilthorpe, J.D., Överby, A.K., (2018). Cell-type- and region-specific restriction of neurotropic flavivirus infection by viperin. $J$. Neuroinflamm., 15, 80. https://doi.org/10.1186/s12974018-1119-3.

61. Perng, Y.-C., Lenschow, D.J., (2018). ISG15 in antiviral immunity and beyond. Nature Rev. Microbiol., 16, 423439. https://doi.org/10.1038/s41579-018-0020-5.

62. Honke, N., Shaabani, N., Zhang, D.-E., Hardt, C., Lang, K. S., (2016). Multiple functions of USP18 e2444-e2444 Cell Death Dis., 7 https://doi.org/10.1038/cddis.2016.326.

63. Huang, X., Sun, S., Wang, X., Fan, F., Zhou, Q., Lu, S., et al., (2019). Mechanistic insights into the SNARE complex disassembly. Sci. Adv., 5, eaau8164. https://doi. org/10.1126/sciadv.aau8164.

64. Jahn, R., Scheller, R.H., (2006). SNAREs-engines for membrane fusion. Nature Rev. Mol. Cell Biol., 7, 631-643. https://doi.org/10.1038/nrm2002.

65. Pirooz, S.D., He, S., Zhang, T., Zhang, X., Zhao, Z., Oh, S., et al., (2014). UVRAG is required for virus entry through combinatorial interaction with the class C-Vps complex and SNAREs. Proc. Natl. Acad. Sci. U. S. A., 111, 2716-2721. https://doi.org/10.1073/pnas.1320629111.

66. Langston, P.K., Nambu, A., Jung, J., Shibata, M., Aksoylar, H.I., Lei, J., et al., (2019). Glycerol phosphate shuttle enzyme GPD2 regulates macrophage inflammatory responses. Nature Immunol., 20, 1186-1195. https://doi. org/10.1038/s41590-019-0453-7.

67. Schoggins, J.W., (2019). Interferon-Stimulated Genes: What Do They All Do? Annu. Rev. Virol., 6, 567584. https://doi.org/10.1146/annurev-virology-092818015756.

68. Tartour, K., Nguyen, X.N., Appourchaux, R., Assil, S., Barateau, V., Bloyet, L.M., et al., (2017). Interference with the production of infectious viral particles and bimodal inhibition of replication are broadly conserved antiviral properties of IFITMs. PLoS Pathog., 13, https://doi.org/ 10.1371/journal.ppat.1006610 e1006610.

69. García-Sastre, A., (2017). Ten Strategies of Interferon Evasion by Viruses. Cell Host Microbe, 22, 176-184. https://doi.org/10.1016/j.chom.2017.07.012.

70. Schulz, K.S., Mossman, K.L., (2016). Viral Evasion Strategies in Type I IFN Signaling - A Summary of Recent Developments. Front. Immunol., 7 https://doi.org/ 10.3389/fimmu.2016.00498.

71. Schoggins, J.W., Macduff, D.A., Imanaka, N., Gainey, M. D., Shrestha, B., Eitson, J.L., et al., (2013). Pan-viral specificity of IFN-induced genes reveals new roles for cGAS in innate immunity. Nature,. https://doi.org/ 10.1038/nature12862.

72. Taylor, H.E., Khatua, A.K., Popik, W., (2014). The innate immune factor apolipoprotein L1 restricts HIV-1 infection. J. Virol., 88, 592-603. https://doi.org/10.1128/JVI.02828-13.

73. Yamane, D., Feng, H., Rivera-Serrano, E.E., Selitsky, S. R., Hirai-Yuki, A., Das, A., et al., (2019). Basal expression of interferon regulatory factor 1 drives intrinsic hepatocyte resistance to multiple RNA viruses. Nature Microbiol., 4, 1096-1104. https://doi.org/10.1038/s41564-019-0425-6.

74. Burke, J.E., McPhail, J.A., Rathinaswamy, M., Jenkins, M. L., (2020). Defining how viruses manipulate lipid phosphoinositides through activation of PI4P kinases to mediate viral replication. FASEB J., $34 \mathrm{https}: / /$ doi.org/ 10.1096/fasebj.2020.34.s1.02060. 1-1.

75. Gillespie, L.K., Hoenen, A., Morgan, G., Mackenzie, J.M., (2010). The Endoplasmic Reticulum Provides the Membrane Platform for Biogenesis of the Flavivirus Replication Complex. J. Virol., 84, 10438-10447. https:// doi.org/10.1128/JVI.00986-10.

76. Olias, P., Etheridge, R.D., Zhang, Y., Holtzman, M.J., Sibley, L.D., (2016). Toxoplasma Effector Recruits the Mi2/NuRD Complex to Repress STAT1 Transcription and Block IFN- $\gamma$-Dependent Gene Expression. Cell Host Microbe, 20, 72-82. https://doi.org/10.1016/ j.chom.2016.06.006.

77. Nusinzon, I., Horvath, C.M., (2003). Interferon-stimulated transcription and innate antiviral immunity require deacetylase activity and histone deacetylase 1. PNAS, 100, 14742-14747. https://doi.org/10.1073/ pnas.2433987100.

78. Vlasáková, J., Nováková, Z., Rossmeislová, L., Kahle, M., Hozák, P., Hodný, Z., (2007). Histone deacetylase inhibitors suppress IFN $\alpha$-induced up-regulation of promyelocytic leukemia protein. Blood, 109, 1373-1380. https://doi.org/10.1182/blood-2006-02-003418. 
79. Saleem, M.A., O'Hare, M.J., Reiser, J., Coward, R.J., Inward, C.D., Farren, T., et al., (2002). A conditionally immortalized human podocyte cell line demonstrating nephrin and podocin expression. J. Am. Soc. Nephrol., 13, 630-638. https://doi.org/10.1681/ASN.V133630.

80. Nakabayashi, H., Taketa, K., Miyano, K., Yamane, T., Sato, J., (1982). Growth of human hepatoma cells lines with differentiated functions in chemically defined medium. Cancer Res., 42, 3858-3863.

81. Buchrieser, J., Dufloo, J., Hubert, M., Monel, B., Planas, D., Rajah, M.M., et al., (2021). Syncytia formation by SARS-CoV-2-infected cells. EMBO J., 40, https://doi.org/ 10.15252/embj.2020107405 e107405.

82. Chazal, M., Beauclair, G., Gracias, S., Najburg, V., SimonLoriere, E., Tangy, F., et al., (2018). RIG-I Recognizes the $5^{\prime}$ Region of Dengue and Zika Virus Genomes. Cell Rep., 24, 320-328. https://doi.org/10.1016/j.celrep.2018.06.047.

83. Boukadida, C., Marnata, C., Montserret, R., Cohen, L., Blumen, B., Gouttenoire, J., et al., (2014). NS2 proteins of $G B$ virus $B$ and hepatitis $C$ virus share common protease activities and membrane topologies. J. Virol., 88, 74267444. https://doi.org/10.1128/JVI.00656-14.

84. Wakita, T., Pietschmann, T., Kato, T., Date, T., Miyamoto, M., Zhao, Z., et al., (2005). Production of infectious hepatitis $\mathrm{C}$ virus in tissue culture from a cloned viral genome. Nature Med., 11, 791-796. https://doi.org/ 10.1038/nm1268.

85. Kaul, A., Woerz, I., Meuleman, P., Leroux-Roels, G., Bartenschlager, R., (2007). Cell culture adaptation of hepatitis $\mathrm{C}$ virus and in vivo viability of an adapted variant. J. Virol., 81, 13168-13179. https://doi.org/ 10.1128/JVI.01362-07.
86. Aicher, S., Kakkanas, A., Cohen, L., Blumen, B., Oprisan, G., Njouom, R., et al., (2018). Differential regulation of the Wnt/beta-catenin pathway by hepatitis $C$ virus recombinants expressing core from various genotypes. Sci. Rep., 8, 11185. https://doi.org/10.1038/s41598-01829078-2.

87. Malo, N., Hanley, J.A., Cerquozzi, S., Pelletier, J., Nadon, R., (2006). Statistical practice in high-throughput screening data analysis. Nature Biotechnol., 24, 167-175. https://doi. org/10.1038/nbt1186.

88. Birmingham, A., Selfors, L.M., Forster, T., Wrobel, D., Kennedy, C.J., Shanks, E., et al., (2009). Statistical Methods for Analysis of High-Throughput RNA Interference Screens. Nature Methods, 6, 569-575. https://doi.org/10.1038/nmeth.1351.

89. McQuin, C., Goodman, A., Chernyshev, V., Kamentsky, L., Cimini, B.A., Karhohs, K.W., et al., (2018). Cell Profiler 3.0: Next-generation image processing for biology. PLOS Biol., 16, https://doi.org/10.1371/journal.pbio.2005970 e2005970.

90. Mutso, M., Saul, S., Rausalu, K., Susova, O., Žusinaite, E., Mahalingam, S., et al., (2017). Reverse genetic system, genetically stable reporter viruses and packaged subgenomic replicon based on a Brazilian Zika virus isolate. J. Gen. Virol., 98, 2712-2724. https://doi.org/ 10.1099/jgv.0.000938.

91. Schwarz, M.C., Sourisseau, M., Espino, M.M., Gray, E.S., Chambers, M.T., Tortorella, D., et al., (2016). Rescue of the 1947 Zika Virus Prototype Strain with a Cytomegalovirus Promoter-Driven cDNA Clone. mSphere, $1 \mathrm{https}: / /$ doi.org/10.1128/mSphere.00246-16. 